\title{
Reactive oxygen species are involved in the signaling of equine sperm chemotaxis
}

\author{
Ayelen Moreno-Irusta', Esteban M Dominguez¹, Clara I Marín-Briggiler², \\ Arturo Matamoros-Volante ${ }^{3}$, Ornella Lucchesi ${ }^{4}$, Claudia N Tomes ${ }^{4}$, Claudia L Treviño ${ }^{3}$, \\ Mariano G Buffone ${ }^{2}$, Ramiro Lascano ${ }^{5}$, Luis Losinno ${ }^{6}$ and Laura C Giojalas ${ }^{1}$ \\ ${ }^{1}$ Centro de Biología Celular y Molecular (FCEFYN-UNC) and Instituto de Investigaciones Biológicas y Tecnológicas \\ (CONICET-UNC), Córdoba, Argentina, ${ }^{2}$ Instituto de Biología y Medicina Experimental (IBYME), CONICET-UBA, \\ Buenos Aires, Argentina, ${ }^{3}$ Departamento de Genética del Desarrollo y Fisiología Molecular, Instituto de \\ Biotecnología, Universidad Nacional Autónoma de México, Cuernavaca, México, ${ }^{4}$ Instituto de Histología y \\ Embriología de Mendoza (IHEM) Dr. Mario H. Burgos-CONICET, Universidad Nacional de Cuyo, Mendoza, \\ Argentina, ${ }^{5}$ Cátedra de Fisiología Vegetal, Facultad de Ciencias Exactas Físicas y Naturales, Universidad Nacional de \\ Córdoba, Córdoba, Argentina and ' ${ }^{6}$ aboratorio de Producción Equina (FAV-UNRC) Rio Cuarto, Córdoba, Argentina \\ Correspondence should be addressed to L C Giojalas; Email: Igiojalas@unc.edu.ar
}

\begin{abstract}
Sperm chemotaxis may facilitate the finding of the oocyte. Only capacitated spermatozoa can orient their movement by chemotaxis, which as well as capacitation, is regulated in part by the cAMP-PKA pathway. Reactive oxygen species (ROS) are produced during sperm capacitation which is closely related to chemotaxis. Then, the ROS participation in the chemotactic signaling can be expected. Here we studied the role of ROS in the chemotaxis signaling of equine spermatozoa which produce high quantities of ROS because of their energy metabolism. The level of capacitated and chemotactic spermatozoa was increased with 0.1 and $0.2 \mathrm{mM}$ hydrogen peroxide $\left(\mathrm{H}_{2} \mathrm{O}_{2}\right)$, which was involved in the chemotactic signaling. By combining a concentration gradient of $\mathrm{H}_{2} \mathrm{O}_{2}$ with inhibitors/ chelators of some of the signaling pathway elements, we showed that the activation of NOX (membrane NADPH oxidase) increases the intracellular ROS which activate the chemotaxis AMPc-PKA pathway. Our results provide evidence about the participation of ROS in the chemotactic signaling mediated by progesterone $(P)$.

Reproduction (2020) 159 423-436
\end{abstract}

\section{Introduction}

Mammalian sperm capacitation is an essential process to guarantee fertilization of the mature oocyte (Austin 1951, Chang 1951). Early events during capacitation are the activation of the cAMP-PKA, of the increase of intracellular calcium $\left(\mathrm{Ca}^{2+}\right)$, the production of reactive oxygen species (ROS), and activation of protein kinases, among others (Nakanishi et al. 2001, O'Flaherty et al. 2006b, Visconti et al. 2011, O'Flaherty 2015, Puga Molina et al. 2018). Once capacitated, sperm become capable of undergoing subsequent fertilization-related processes when exposed to the appropriate stimuli, including the chemotaxis response (Eisenbach \& Giojalas 2006, Giojalas et al. 2015), the induced acrosome reaction (AR; Buffone 2016), the zona pellucida binding and penetration, and finally, the fusion with the plasma membrane of the female gamete (Florman \& Fissore 2014).

It is well established that mammalian sperm capacitation is an oxidative event (Aitken et al. 1995, de Lamirande et al. 1997, O'Flaherty 2015). Indeed, the early production of ROS evidenced by an increase in the concentrations of superoxide anion $\left(\mathrm{O}_{2}{ }^{-}-\right)$, hydrogen peroxide $\left(\mathrm{H}_{2} \mathrm{O}_{2}\right)$, nitric oxide $\left(\mathrm{No}^{*}\right)$, and peroxynitrite $\left(\mathrm{ONOO}^{-}\right)$, has been reported during capacitation (de Lamirande \& Gagnon 1995, Herrero et al. 2003, O'Flaherty et al. 2003, 2004). In the spermatozoon, the intracellular ROS are produced by numerous alternative sources including mitochondria, lipoxygenase as well as various oxidases (Bize et al. 1991, Griveau et al. 1994, Aitken et al. 1995, Baumber et al. 2003, O'Flaherty 2015, Aitken 2018). The role of ROS during capacitation involves the activation of molecules located on the plasma membrane and in other sperm compartments. For instance, $\mathrm{O}_{2}{ }^{-}$and $\mathrm{NO}{ }^{\bullet}$ would participate activating an AC, which is known to produce cAMP (Zhang \& Zheng 1996, Herrero et al. 2000, O'Flaherty 2015), activating in turn a protein kinase $\mathrm{A}$ (PKA), essential step to support tyrosine phosphorylation associated with sperm capacitation in all species studied to date (Visconti et al. 1995a, Visconti et al. 1995b, Lewis \& Aitken 2001, 
Lefièvre et al. 2002, Ecroyd et al. 2003, O'Flaherty et al. 2004). In mammalian spermatozoa as well as in somatic cells, ROS are maintained at physiological levels by an antioxidant system that includes enzymes such as superoxide dismutase (SOD), catalase (CAT), glutathione peroxidases (GPXs), thioredoxins (TRXs), peroxiredoxins (PRDXs), and other molecules (Halliwell \& Gutteridge 2015). When the antioxidant system is unbalanced, the excess of ROS becomes a harmful product for cell metabolism (Halliwell \& Gutteridge 2015). The abnormal increase in intracellular ROS levels is termed oxidative stress and is the result of a disequilibrium in either an excessive production of ROS and/or a reduction in the antioxidant activity (Halliwell 2006, Halliwell \& Gutteridge 2015). The oxidative damage affects all cell components, altering several sperm functions like motility, mitochondrial activity, capacitation and acrosome reaction, also causing DNA fragmentation (Jones \& Mann 1977, Jones et al. 1979, Aitken et al. 1989, de Lamirande \& Gagnon 1995, Sikka et al. 1995, de Lamirande et al. 1997, Griveau \& Le Lannou 1997, Rivlin et al. 2004), which in turn leads to infertility (Aitken et al. 1989, Gagnon et al. 1991, Agarwal et al. 2006).

Sperm chemotaxis, a chemical guiding mechanism that may orient spermatozoa to the egg surface (Eisenbach \& Giojalas 2006, Giojalas et al. 2015), has also been reported to be affected by the excess of ROS (Sánchez et al. 2010). Even though spermatozoa can be attracted by several molecules, progesterone becomes of physiological importance since it is secreted by the cells that surround the oocyte, forming a stable concentration gradient along the cumulus oophorus (Teves et al. 2006, Guidobaldi et al. 2008). Interestingly, P induces chemotaxis at very low concentrations (pM), in capacitated spermatozoa of several species (Teves et al. 2006, 2009, 2010, Blengini et al. 2011, Gatica et al. 2013, Ernesto et al. 2015, Franchi et al. 2016, Guidobaldi et al. 2017, Dominguez et al. 2018), and the chemotaxis signaling has been partially described for human spermatozoa (Teves et al. 2009, Giojalas et al. 2015).

Given that equine spermatozoa produce high levels of ROS because of their energy metabolism (Gibb et al. 2014) and that ROS are intermediaries in the signaling pathway of capacitation, process closely associated to chemotaxis, the aim of this work was to study whether there is a critical level of ROS that stimulates the capacitated-chemotactic state of stallion sperm, and whether ROS are involved in the chemotaxis signaling in this species.

\section{Materials and methods \\ Chemicals and reagents}

Unless otherwise specified, chemicals were purchased from Sigma-Aldrich. Mouse monoclonal anti-phosphotyrosine (anti-PY) antibody (clone 4G10, cat \#05-321) was obtained from EMD Millipore. Alexa Fluor 488-conjugated anti-mouse secondary antibody was purchased from Invitrogen (Thermo Fisher Scientific) and horseradish peroxidase (HRP)-conjugated anti mouse antibody was from Vector Lab. Inc. (Burlingame, CA, USA). The inhibitor and chelators used were PF431396 (Selleck Biochem), H89 dihydrochloride (Cayman Chemical), TAT-cAMP sponge was produced in the lab of Dr Claudia N. Tomes (IHEM, Argentina) (Lucchesi et al. 2016).

\section{Sperm preparation and capacitation}

Cryopreserved equine semen samples $\left(200 \times 10^{6}\right.$ sperm $/ \mathrm{mL}$, $0.5 \mathrm{~mL}$ per straw) of proven fertility from Polo Pony and Criollo breeds were donated by the Laboratorio de Producción Equina, Facultad de Agronomía y Veterinaria, Universidad Nacional de Río Cuarto (Córdoba, Argentina). For each set of experiments three ejaculates from at least three different stallions were included. Biggers, Whitten and Whittingham medium (BWW; Biggers et al. 1971) was used, supplemented with $5 \mathrm{U} / \mathrm{mL}$ penicillin, $5 \mathrm{mg} / \mathrm{mL}$ streptomycin, and $20 \mathrm{mM}$ HEPES buffer (osmolarity of $300 \mathrm{mOsm} / \mathrm{kg}$ ). This medium was used for non-capacitating assays (NonCAP), while for assays requiring capacitated spermatozoa, the medium (CAP) was supplemented with $3 \mathrm{mM}$ pentoxifylline, $25 \mathrm{mM} \mathrm{NaHCO}_{3}$ and $0.3 \%(\mathrm{w} / \mathrm{v})$ of BSA. Semen samples were thawed at $38.5^{\circ} \mathrm{C}$ for $30 \mathrm{~s}$, and seminal plasma and cryoprotectant were removed by the migration-sedimentation technique (Risopatrón et al. 1996), with culture medium (either NonCAP or CAP) for $45 \mathrm{~min}$ at $38.5^{\circ} \mathrm{C}$, in an atmosphere of $5 \% \mathrm{CO}_{2}$ in air. In the case of CAP medium, this period was considered as capacitating time (Dominguez 2019).

\section{Sperm parameters associated to capacitation}

\section{Protein tyrosine phosphorylation (PY) determined by immunocytochemistry}

The occurrence of phosphorylation on tyrosine residues was determined by immunofluorescence according to GonzálezFernández et al. (2013). Sperm samples were fixed for 20 min in $2 \%(\mathrm{w} / \mathrm{v})$ formaldehyde in PBS, washed by centrifugation, suspended in PBS, placed on a slide pretreated with poly-L-lysine and let dry in air. Spermatozoa were permeabilized with $0.1 \%(\mathrm{v} / \mathrm{v})$ Triton X-100 in PBS for $10 \mathrm{~min}$, washed three times with PBS, incubated for $1 \mathrm{~h}$ in PBS containing 3\% (w/v) BSA (blocking solution), and washed three times with PBS. Spermatozoa were incubated with or without (negative control) the anti-phosphotyrosine MAB (4G10 mAb) diluted 1:500 in PBS with $3 \%(\mathrm{w} / \mathrm{v})$ BSA overnight at $4{ }^{\circ} \mathrm{C}$. After, washing with PBS, the cells were incubated with the secondary antibody, Alexa Fluor 488-conjugated goat anti-mouse IgG (1:500), for $1 \mathrm{~h}$ at room temperature in the dark, and then washed three times with PBS. A drop of a fluorescence enhancer was added (Vectashield, Vector, Burlingame, CA, USA) to improve and preserve cell fluorescence. At least 200 cells per treatment were observed at $1000 \times$ magnification under a fluorescence microscope (Olympus BX 50). Four staining patterns were observed as follows: only principal piece, both head and principal piece, only head and unlabeled. The first two patterns are associated with capacitation, while the other 
two are not (Pommer et al. 2003, Matamoros-Volante et al. 2018). The percentage of spermatozoa showing the two capacitation patterns was recorded.

\section{Protein tyrosine phosphorylation (PY) determined by Western blot}

The occurrence of phosphorylation on tyrosine residues was also determined by Western blot according to Marín-Briggiler et al. (1999). To obtain the sperm protein extracts, sperm of each treatment were centrifuged for $5 \mathrm{~min}$ at $600 \mathrm{~g}$, the sperm pellets were resuspended with Laemmli sample buffer, heated, centrifuged, and the supernatants were recovered. Samples were supplemented with 5\% 2-bmercaptoethanol, boiled for $10 \mathrm{~min}$, stored at $-20^{\circ} \mathrm{C}$ until used. The extract of sperm samples under different treatments were sent for WB analysis from CEBICEM to IBYME, Buenos Aires. Solubilized proteins (corresponding to $2 \times 10^{6}$ cells per lane) were subjected to SDS-PAGE in $10 \%$ polyacrylamide gels and Western immunoblotting, using anti-pY (1:1000), anti-tubulin (1:1500) and anti-mouse HRP-conjugated secondary antibody (1:2000). The reactive bands were detected by enhanced chemiluminescence (ECL kit, GE-Amersham) using standard procedures.

\section{Induced acrosome reaction}

The ability of spermatozoa to undergo the induced AR was determined as an indirect indicator of the level of capacitated spermatozoa (Jaiswal et al. 1998). The acrosome status was detected in alive spermatozoa using Pisum sativum agglutinin fluorescein staining (PSA-FITC; Zoppino et al. 2012, Bustos et al. 2014). Briefly, sperm suspensions were divided into two aliquots, which were incubated with or without $8 \mu \mathrm{M}$ calcium ionophore A23187 and $10 \mu \mathrm{g} / \mathrm{mL}$ PSA-FITC in culture medium, at $38.5^{\circ} \mathrm{C}$ for $30 \mathrm{~min}$. Then, the sperm suspensions were fixed in $2 \%(\mathrm{w} / \mathrm{v})$ formaldehyde in PBS for $20 \mathrm{~min}$ at room temperature, washed by centrifugation in distilled water, and the pellets were smeared on slides and allowed to air dry. The status of the acrosome was observed in at least 200 cells at $1000 \times$ magnification under a fluorescence microscope (Olympus BX 50), where acrosome-reacted spermatozoa presented a green fluorescent acrosome, while the ones with intact acrosome were unlabeled. The net percentage of AR was determined as the difference in the AR percentage between induced and spontaneous acrosome-reacted spermatozoa.

\section{Sperm chemotaxis}

This parameter was evaluated by means of the Sperm Selection Assay (SSA) which recruits capacitated sperm by chemotaxis (Gatica et al. 2013). This assay was run under conditions defined for equine spermatozoa according to Dominguez (2019). Briefly, the device used in the SSA consists of two wells, in which the sperm suspension at $2 \times 10^{6} / \mathrm{mL}$ is placed in one well (W1) and the attractant solution or culture medium as negative control) in the other (W2). The two wells are connected by a tube, through which the attractant diffuses from $W 2$ to $W 1$, forming a concentration gradient which stimulates sperm chemotaxis. The SSA device was incubated at $38.5^{\circ} \mathrm{C}$, in an atmosphere of $5 \% \mathrm{CO}_{2}$ on air for $10 \mathrm{~min}$. At the end of the assay, the net sperm accumulation in W2 was determined. This parameter was calculated as the difference in the percentage of spermatozoa recovered from W2 with or without attractants.

\section{Sperm motility and other kinematic parameters}

Sperm motility was determined by video microscopy and image analysis according to Giaretta et al. (2017) with brief modifications. A light microscope (Nikon Instruments Inc.) equipped with a $10 \times$ negative phase contrast plan objective and a digital video camera Nikon CMOS USB 2.0 (Nikon Instruments Inc) was used. The videos were recorded for $5 \mathrm{~s}$ at a resolution of $800 \times 600$ and 30 frames/s using the NIS Elements Imaging Software 3.01 (Nikon Instruments Inc.), and then converted to avi format. Ten microliters of spermatozoa at a concentration of $10 \times 10^{6} \mathrm{sperm} / \mathrm{mL}$ were put on a slide previously warmed at $38.5^{\circ} \mathrm{C}$, and covered with a $18 \times 18-\mathrm{mm}^{2}$ coverslip. The slide was placed over a thermal plate $\left(38.5^{\circ} \mathrm{C}\right)$, and $5 \mathrm{~s}$ records were taken from five different fields selected at random. The percentage of sperm motility and other kinematic parameters (curvilinear velocity; mean traverse velocity; straight-line velocity) were determined by CASA-bmg plugin (Giaretta et al. 2017), using Imagej software (version 1.46j; NIH). Only samples exhibiting $\geq 90 \%$ of motile spermatozoa after sperm separation were included in the assays.

\section{Flow cytometry}

Unless otherwise stated, flow cytometry was performed using an Acuri C6 flow cytometer (Becton Dickinson) with a 488-nm argon ion laser. Emission measurements were made using 530/30 $\mathrm{nm}$ band pass (green/FL-1), 585/42 $\mathrm{nm}$ band pass (red/FL-2), 661/16 nm band pass (red/FL- 3), and $670 \mathrm{~nm}$ long pass (far red/FL-4) filters. Debris was gated out using a forward scatter/side scatter dot plot, and 100,000 cells were analyzed per sample. All data were analyzed using Flow)o software v10.0.7 (Becton Dickinson).

\section{Viability}

Sperm viability was assessed using the LIVE/DEAD TM Viability/ Cytotoxicity Kit (Invitrogen). Briefly, spermatozoa were incubated at $38.5^{\circ} \mathrm{C}$ for $20 \mathrm{~min}$ with $0.5 \mu \mathrm{M}$ stain solution, according to the manufacturer's instructions. Sperm samples were analyzed by flow cytometry and classified as either viable or not viable, using a snap-frozen ('dead') positive control for gating purposes. Results were expressed as percentage of living cells.

\section{ROS production}

Cytoplasmic and mitochondrial superoxide anion production was measured according to Gibb et al. (2014). Briefly, spermatozoa were incubated with $2 \mu \mathrm{M}$ dihydroethidium (DHE; Molecular Probes) and $0.5 \mu \mathrm{M}$ Calcein-AM viability stain (Molecular Probes), for $15 \mathrm{~min}$ at $38.5^{\circ} \mathrm{C}$. Samples were assessed by flow cytometry gating the alive sperm population 
(positive for Calcein-AM) and positive for DHE (evidencing cytoplasmic ROS). Mitochondrial superoxide production was measured by incubating spermatozoa with $2 \mu \mathrm{M}$ MitoSOX Red (MSR; Molecular Probes) and $0.5 \mu \mathrm{M}$ Calcein-AM (Molecular Probes) for $15 \mathrm{~min}$ at $38.5^{\circ} \mathrm{C}$. Samples were assessed by flow cytometry gating the alive sperm population (positive for Calcein-AM and for MitoSOX evidencing mitochondrial ROS). As a positive control for both MSR and DHE assays, $100 \mathrm{nM}$ phorbol 12-myristate13-acetate (PMA) was used. Results were expressed as the mean fluorescence intensity (MFI).

\section{Lipid peroxidation}

Oxidative degradation of lipids was measured using the green fluorescence marker, BODIPY C11 kit (Molecular Probes Inc.), according to Aitken et al. (2007). In brief, $2 \times 10^{6}$ spermatozoa were incubated with BODIPY C11 (final concentration $5 \mu \mathrm{M}$ ) during $30 \mathrm{~min}$ at $38.5^{\circ} \mathrm{C}$ and washed prior to flow cytometry analysis. As positive controls, aliquots of sperm suspensions were additionally treated with $2 \mathrm{mM}$ of $\mathrm{H}_{2} \mathrm{O}_{2}$ to induce lipid peroxidation. The results were expressed as the percentage of cells exhibiting green fluorescent labeling.

\section{Mitochondrial membrane potential}

Mitochondrial membrane potential $(\Delta \Psi \mathrm{m})$ was determined by flow cytometry using the JC-1 probe as previously described by Gravance et al. (2000). Aliquots with $2 \times 10^{6}$ sperm per $\mathrm{ml}$ were incubated with a $500 \mathrm{nM}$ solution of JC-1 for $15 \mathrm{~min}$ at $38.5^{\circ} \mathrm{C}$. As a negative control, a $2 \mathrm{mM}$ solution of Carbonylcy anide-m-chlorophenylhydrazone cyanide (CCCP) was used for $30 \mathrm{~min}$ at room temperature, which is an uncoupler of the oxidative phosphorylation.

\section{Oxidative DNA damage}

Oxidative guanine adducts (8-hydroxy-20-deoxyguanosine $[8 \mathrm{OHdG}]$ ) were immunolabeled and then analyzed by flow cytometry (Gibb et al. 2014). Aliquots with $2 \times 10^{6}$ sperm per $\mathrm{mL}$ were washed by centrifugation twice in PBS for $5 \mathrm{~min}$ at $600 \mathrm{~g}$. Then, chromatin was relaxed to facilitate probe access by incubation with a $2 \mathrm{mM}$ solution of dithiothreitols (DTT) for $15 \mathrm{~min}$ at $38.5^{\circ} \mathrm{C}$. Spermatozoa were fixed and permeabilized with $4 \%$ formaldehyde in PBS and $0.05 \%$ Triton X-100 in PBS, respectively. The non-specific antigenic sites were blocked with a $5 \%$ goat serum solution in $\mathrm{PBS} / 0.5 \%$ Triton $\mathrm{X}-100$, for $2 \mathrm{~h}$ at room temperature. Subsequently, the cells were incubated with the monoclonal anti-8OHdG mouse antibody $(1: 500$ in a solution of $1.5 \%$ goat serum in PBS/0.5\% Triton $\mathrm{X}$-100) overnight at $4^{\circ} \mathrm{C}$. The cells were then washed with PBS for $5 \mathrm{~min}$ and centrifuged for $5 \mathrm{~min}$ at 2,300 $\mathrm{g}$, followed by an incubation of $1 \mathrm{~h}$ with the FITC-conjugated anti-mouse secondary antibody (1:500 in a solution of $1.5 \%$ goat serumPBS/0.5\% Triton X-100). As positive controls, aliquots of sperm suspensions were additionally treated with $2 \mathrm{mM}$ of $\mathrm{H}_{2} \mathrm{O}_{2}$ for 60 min to induce oxidative DNA damage. The cells were then centrifuged, resuspended in PBS, and analyzed. The results were expressed as the percentage of spermatozoa with green fluorescent labeling.

\section{Statistical analysis}

Data were expressed as the mean \pm standard error (S.E.M.) of at least three independent experiments. Differences between treatments were determined by means of one-way ANOVA, where data were previously verified to accomplish the parametric assumptions of homogeneity of variances and normality using Anderson-Darling test. Differences between pair of means were determined with a posteriori Tukey test. Statistical analysis was performed with the GraphPad Prism 6.01, considering statistically significant differences at a level of confidence $\leq 0.05$.

\section{Results}

\section{Endogenous production of ROS during sperm capacitation}

In contrast to other mammalian species, equine spermatozoa use oxidative phosphorylation as the main energy source, generating considerable amounts of ROS in the mitochondria (Gibb \& Aitken 2016). We determined the increase of endogenous $\mathrm{O}_{2}{ }^{-}-$in the cytoplasm and mitochondria before and after sperm incubation under NonCAP and CAP media (Fig. 1A and $\mathrm{B}$ ). A significant increase in $\mathrm{O}_{2}{ }^{--}$production was observed in mitochondria after 45 min of incubation under CAP condition as compared to time 0 and 45 min in NonCAP medium $(P=0.0006$; Fig. 1B). This result show that, in equine spermatozoa, the level of $\mathrm{O}_{2}{ }^{\bullet-}$ increases as a result of sperm incubation under capacitating conditions.

\section{Characterization of the effect of exogenous $\mathrm{H}_{2} \mathrm{O}_{2}$ on sperm capacitation and chemotaxis}

In order to define the range of exogenous $\mathrm{H}_{2} \mathrm{O}_{2}$ necessary to stimulate equine sperm capacitation, spermatozoa were incubated under capacitating and noncapacitating conditions, in the absence or presence of different $\mathrm{H}_{2} \mathrm{O}_{2}$ concentrations. A mixture of antioxidants (CAT, catalase; SOD, superoxide dismutase) was used as negative control. At the end of the incubation time, sperm parameters associated with capacitation (\% PY positive cells labeled in the principal piece and $\left.\% A R_{i}\right)$, chemotaxis (\% sperm accumulation in W2), vitality, motility and other kinematic parameters were evaluated in each treatment (Fig. 2A).

Under capacitating conditions, incubation with 0.1 and $0.2 \mathrm{mM} \mathrm{H}_{2} \mathrm{O}_{2}$ led to a significant increase in the $\%$ PY positive cells (Fig. 2B and C), \% AR $($ Fig. 2F), and chemotaxis (Fig. 2G) as compared to the absence of $\mathrm{H}_{2} \mathrm{O}_{2}(P=0.0003, P=0.0002, P=0.0002$, respectively). However, in the presence of $0.4 \mathrm{mM} \mathrm{H}_{2} \mathrm{O} 2$ a reduction in the values of all these parameters was observed (Fig. 2B, C, D, E, F and G). Similar results were obtained for PY levels assessed by Western blot (Fig. 2D). In general, when the cells were incubated under non-capacitating conditions, the $\mathrm{H}_{2} \mathrm{O}_{2}$ concentrations affected sperm physiological 


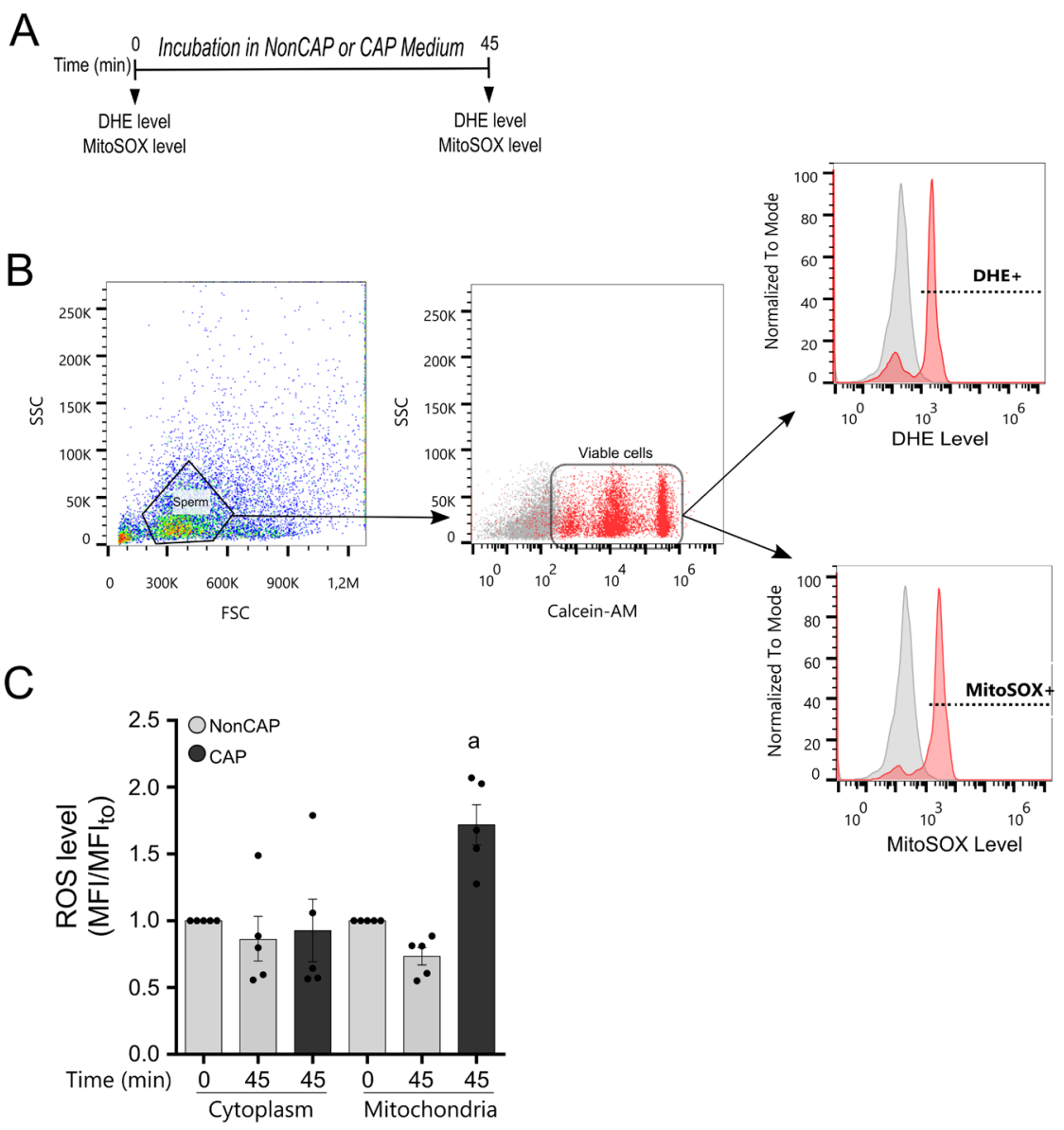

Figure 1 Endogenous production of ROS during sperm capacitation. (A) Experimental design where downward arrowhead indicates measured parameter. (B) Gating strategy for data analysis, spermatozoa were selected on a forward and side scatter plot (left panel) and then only live spermatozoa (Calcein-AM positives; central panel) were further gated to determine DHE (upper right panel) or MitoSOX (lower right panel) mean fluorescence intensity. Sample data at time 0 (red) and that of unlabeled control (gray) are shown (C) Relative level of superoxide anion ( $\mathrm{FMFI} / \mathrm{FMFI}(\mathrm{t} 0)$ ) in cytoplasm (by DHE) and in mitochondria (by MitoSOX), at $0 \mathrm{~min}$ and 45 min of incubation under non capacitating (NonCAP in grey) or capacitating conditions (CAP in black). MFI, medium fluorescence intensity. The black dots represent individual experiments. The results are expressed normalized with respect to the control at t0, as the mean \pm S.E.M. of at least five experiments. asignificant difference vs t0 $(P<0.05)$. parameters in a similar way than that of CAP medium, but with less magnitude. Sperm viability and kinematic parameters remained constant even at $0.4 \mathrm{mM} \mathrm{H}_{2} \mathrm{O}_{2}$ $(P=0.616$ and $P=0.9861$ respectively; Fig. $2 \mathrm{H}$ and $\mathrm{I})$. In contrast, a slight decrease in the percentage of motile cells was observed with $0.2 \mathrm{mM} \mathrm{H}_{2} \mathrm{O}_{2}$ while a dramatic decrease in motility was observed with $0.4 \mathrm{mM} \mathrm{H}_{2} \mathrm{O}_{2}$ $(P<0.0001 ;$ Fig. $2 \mathrm{H})$. Since under capacitation conditions there was a tendency of $0.2 \mathrm{mM} \mathrm{H}_{2} \mathrm{O}_{2}$ concentration to stimulate a higher effect on sperm function in comparison to $0.1 \mathrm{mM} \mathrm{H}_{2} \mathrm{O}_{2}$ (Fig. 2B, C, D, E, F and G), with no effect on viability or most sperm kinematic parameters (Fig. $2 \mathrm{H}$ and I), we used $0.2 \mathrm{mM} \mathrm{H}_{2} \mathrm{O}_{2}$ hereafter. Consistently, the antioxidants significantly decreased the values of the three sperm parameters to levels similar to the control (Fig. 2G). In summary, low levels of exogenous $\mathrm{H}_{2} \mathrm{O}_{2}$ stimulate sperm parameters associated with capacitation, while higher concentrations negatively affected those parameters and sperm motility.

\section{Effects of exogenous $\mathrm{H}_{2} \mathrm{O}_{2}$ on the oxidative state of spermatozoa}

The level of oxidative stress was evaluated in sperm incubated in the presence or absence of $0.2 \mathrm{mM} \mathrm{H}_{2} \mathrm{O}_{2}$ (concentration that stimulates capacitation), $0.4 \mathrm{mM} \mathrm{H}_{2} \mathrm{O}_{2}$ (concentration that inhibits capacitation), and $2 \mathrm{mM}$ of $\mathrm{H}_{2} \mathrm{O}_{2}$ (positive control for oxidative stress; Barbonetti et al. 2016), determining the levels of cytoplasmic and mitochondrial ROS, lipid peroxidation, mitochondrial membrane potential $(\Delta \psi \mathrm{m})$ and DNA oxidation (Fig. $3 \mathrm{~A})$. When the cells were exposed to 0.2 and $0.4 \mathrm{mM} \mathrm{H}_{2} \mathrm{O}_{2}$, the level of cytoplasmic and mitochondrial $\mathrm{O}_{2}{ }^{{ }^{-}}$, as well as DNA oxidation did not change compared to the negative control, but were significantly decreased in comparison to the positive control $(P=0.0139, P=0.0204$ and $P=0.0161$, respectively) (Fig. $3 \mathrm{~B}, \mathrm{C}$ and $\mathrm{D})$. The mitochondrial membrane potential was constant at any $\mathrm{H}_{2} \mathrm{O}_{2}$ concentration, even with $2 \mathrm{mM}$ (positive control); hence, in this set of experiments the mitochondrial uncoupler CCCP was used as a negative control $(P<0.0001$; Fig. 3E). Lipid peroxidation was not affected under $0.2 \mathrm{mM}$ of $\mathrm{H}_{2} \mathrm{O}_{2}$, but it was significantly increased under higher $\mathrm{H}_{2} \mathrm{O}_{2}$ concentrations $(P=0.0007$; Fig. 3F). These results show that the concentration of $\mathrm{H}_{2} \mathrm{O}_{2}$ that stimulates the sperm function associated to capacitation did not produce oxidative stress in spermatozoa.

\section{ROS as mediators of the chemotaxis signaling}

Since equine spermatozoa exposed to a chemotactic $P$ gradient have significantly higher levels of mitochondrial 
A

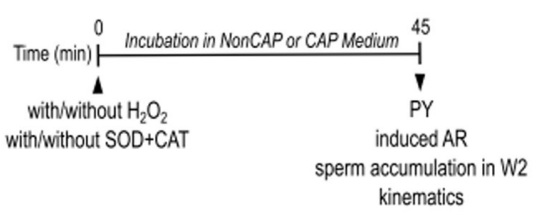

B

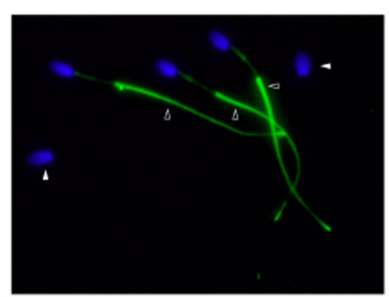

D

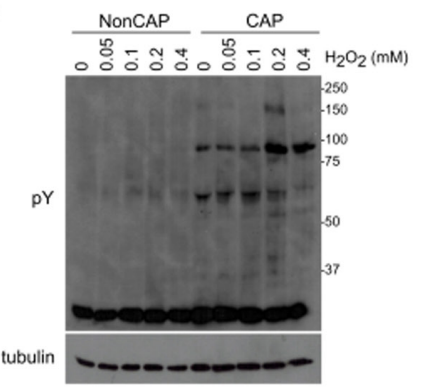

$\mathrm{F}$

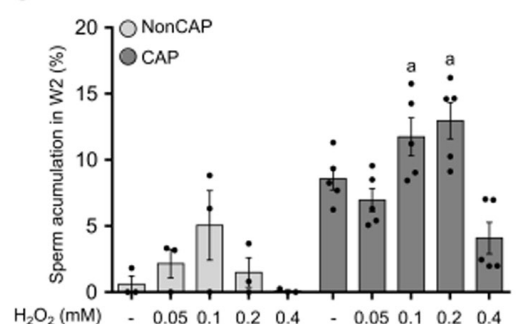

$\mathrm{H}$

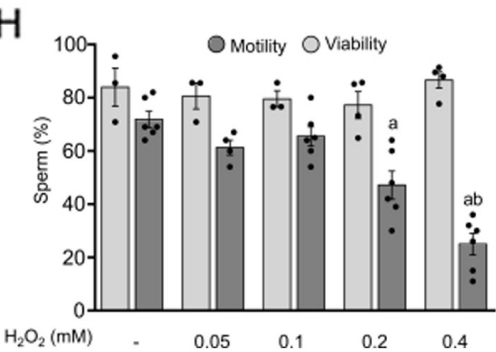

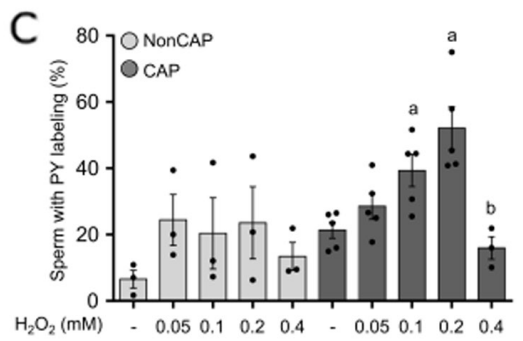

E

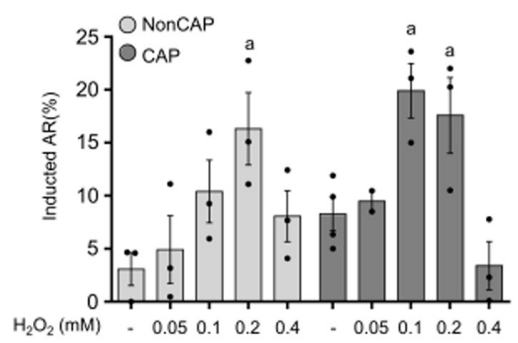

G

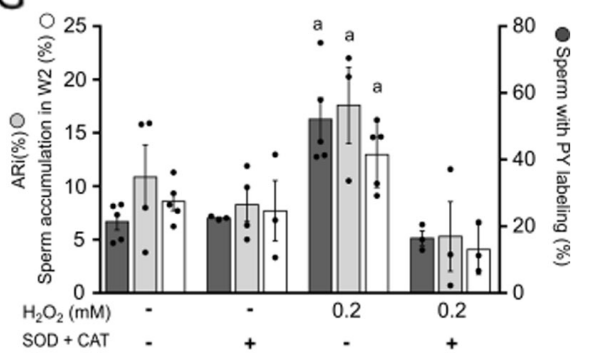

I

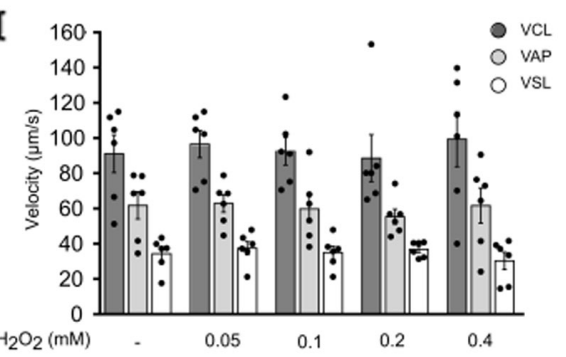

Figure 2 Induction of capacitation and chemotaxis by exogenous $\mathrm{H}_{2} \mathrm{O}_{2}$ in equine sperm. (A) Experimental design, upward arrowhead indicates treatment, downward arrowhead indicates measured parameter; (B) Representative microphotography of PY immunostaining (green) and nucleus (blue), empty arrowhead shows non labeling for PY and filled arrowhead show positive labeling for PY; (C) Percentage of sperm with PY labeling in principal piece under CAP and NonCAP conditions; (D) PY patterns in sperm incubated under these conditions; $(\mathrm{E})$

Percentage of sperm ARi. under CAP and NonCAP conditions; (F) Percentage of sperm accumulation in W2; (G) Effect of antioxidants (SOD + CAT, $1000 \mathrm{U} / \mathrm{mL}$ ) on sperm parameters associated to capacitation. (H) Motility (dark grey) and viability (light grey) of sperm exposed to different concentrations of $\mathrm{H}_{2} \mathrm{O}_{2}$; (I) Sperm velocity under different concentrations of $\mathrm{H}_{2} \mathrm{O}_{2}$. PY, protein tyrosine phosphorylation; $\mathrm{ARi}$, induced acrosomal reaction; CAP, capacitating medium; NonCAP, no capacitating medium; $\mathrm{VCL}$, curvilinear velocity (dark grey bars); VAP, mean trajectory velocity (light grey bars); VSL, straight line velocity (white bars). The black dots represent individual experiments. The results are presented as the mean \pm S.E.M. of at least five experiments performed with ejaculates from three different horses. ${ }^{a}$ Significant difference vs without $\mathrm{H}_{2} \mathrm{O}_{2}$ or antioxidants, ${ }^{\text {b}}$ Significant differences vs $0.2 \mathrm{mM}$ of $\mathrm{H}_{2} \mathrm{O}_{2}(P<0.05)$. and cytoplasmic ROS (Dominguez 2019), it would be possible that ROS may participate in the molecular mechanism of chemotaxis toward P. Our hypothesis is that by removing ROS by antioxidants chemotaxis would be inhibited. To test this hypothesis, after capacitation spermatozoa were incubated with different concentrations of antioxidants (a combination of CAT and SOD which scavenge ROS), and then exposed to a gradient of $\mathrm{P}$ in the sperm selection device, where the $\%$ sperm accumulation in W2 and kinematic parameters were determined (Fig. 4A). The treatment with antioxidants significantly reduced the chemotactic response to $\mathrm{P}$ in a dose-dependent manner $(P=0.0015$; Fig. 4B). Neither sperm velocity nor sperm motility were affected by any concentration of antioxidants $\left(P=0.6494\right.$; Fig. 4C). To evaluate whether $\mathrm{H}_{2} \mathrm{O}_{2}$ act as a second messenger during the chemotaxis response, spermatozoa were exposed to a concentration gradient 
A

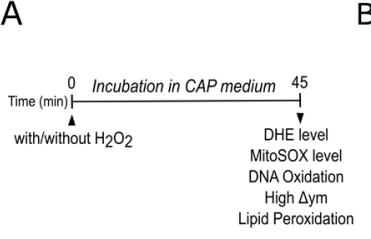

D
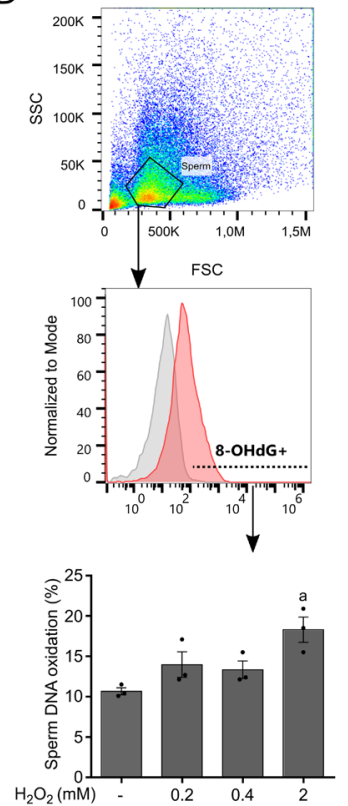
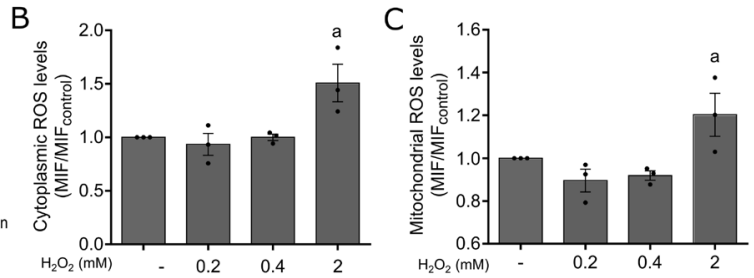

E
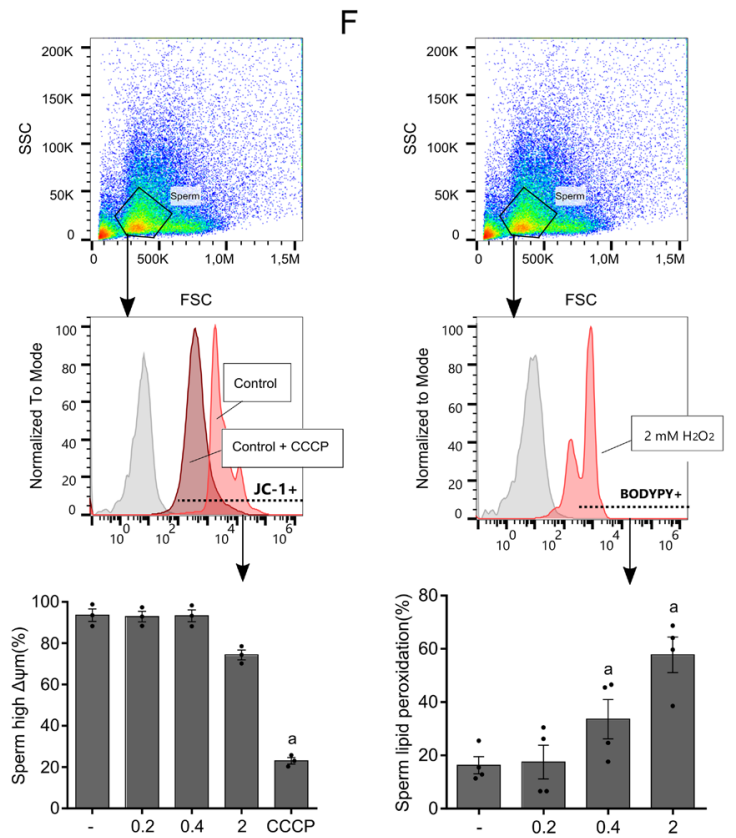

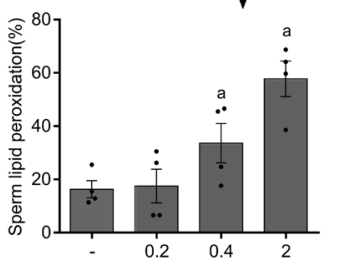

Figure 3 Oxidative stress parameters as a function of exogenous $\mathrm{H}_{2} \mathrm{O}_{2}$ concentration. (A) Experimental design where upward arrowhead indicates treatment applied, and downward arrowhead the measured parameters; (B) Cytoplasmic ROS levels; (C) Mitochondrial ROS levels; (D)\% Sperm DNA oxidation; (E) \%Sperm with high mitochondrial membrane potential (high $\Delta \psi \mathrm{m}) ;(\mathrm{F}) \%$ Sperm lipid peroxidation. Gating strategy for data analysis are shown, spermatozoa were selected on a forward and side scatter plot (upper panels), and these cell populations were used to carry out the corresponding histogram for each studied parameter (D, E and F). CCCP, mitochondrial uncoupling. The black dots represent individual experiments. The results are presented as the mean \pm S.E.M. of at least three experiments carried out with ejaculates from

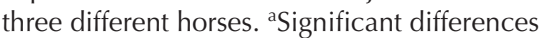
vs without $\mathrm{H}_{2} \mathrm{O}_{2}(P<0.05)$. generated by $0.2 \mathrm{mM}$ of $\mathrm{H}_{2} \mathrm{O}_{2}$ (which is permeable to the plasma membrane) in the absence of $\mathrm{P}$ (the extracellular ligand that stimulates chemotaxis). Therefore, $\mathrm{H}_{2} \mathrm{O}_{2}$ would act as a second messenger, by inducing per se the orientation of the sperm movement toward W2. We and other laboratories have used this strategy to study the participation of second messengers on the chemotactic response (Gundersen \& Barrett 1980, Teves et al. 2009). Capacitated spermatozoa were exposed in the SSA to a gradient generated by $10 \mathrm{pM}$ of $\mathrm{P}$ (as a positive control) or by $0.2 \mathrm{mM}$ of $\mathrm{H}_{2} \mathrm{O}_{2}$ (Fig. 4D). When spermatozoa were exposed to a gradient generated by $0.2 \mathrm{mM}$ of $\mathrm{H}_{2} \mathrm{O}_{2}$, the \% of sperm accumulation in W2 was similar to that observed under a $\mathrm{P}$ gradient $(P=0.1543$; Fig. $4 \mathrm{E})$. We next performed control experiments to verify that sperm accumulation observed in W2 containing $\mathrm{H}_{2} \mathrm{O}_{2}$ was due to chemotaxis rather than to other kinematic processes (Giojalas et al. 2015, Fig. 4F). The \% of sperm accumulated in $\mathrm{W} 2$ was close to zero in the absence of a $\mathrm{H}_{2} \mathrm{O}_{2}$ gradient, showing a negative value when sperm faced a descending $\mathrm{H}_{2} \mathrm{O}_{2}$ gradient, as compared to the ascending $\mathrm{H}_{2} \mathrm{O}_{2}$ gradient $(P<0.0001$; Fig. 4G). These results are consistent with a sperm accumulation in W2 due only to chemotaxis and show that ROS may act as a second messenger in the molecular mechanism of chemotaxis toward $\mathrm{P}$.

\section{Sequence of chemotaxis intracellular events mediated by $\mathrm{H}_{2} \mathrm{O}_{2}$}

Since ROS are known to participate in the activation of the AMPc-PKA capacitation signaling, where this pathway is also involved in the initiation of sperm chemotaxis, we next studied in which steps of this chemotactic pathway $\mathrm{H}_{2} \mathrm{O}_{2}$ were involved (Teves et al. 2009). After capacitation, spermatozoa were incubated with different concentrations of inhibitors or chelators, and then exposed to a concentration gradient generated by $0.2 \mathrm{mM}$ of $\mathrm{H}_{2} \mathrm{O}_{2}$ in the SSA device, determining sperm accumulation in W2 and kinematic parameters. As a positive control, spermatozoa were exposed to a gradient generated by $10 \mathrm{pM}$ of $\mathrm{P}$ (Fig. 5A). To explore whether $\mathrm{H}_{2} \mathrm{O}_{2}$ are involved before or after the activation of adenylate cyclase (AC), capacitated spermatozoa were incubated with different concentrations of a protein permeable to the cell membrane that scavenges cytoplasmic cAMP (TAT-cAMP sponge; Lucchesi et al. 2016). The treatment with TAT-CAMP sponge significantly decreased the chemotactic response of spermatozoa exposed to a concentration gradient of $\mathrm{H}_{2} \mathrm{O}_{2}$ in a dosedependent manner $(P=0.0008)$, similarly to the response observed in the positive $\mathrm{P}$ control (Fig. 5B). Thus, the increase of $\mathrm{H}_{2} \mathrm{O}_{2}$ occurs prior to the activation of 

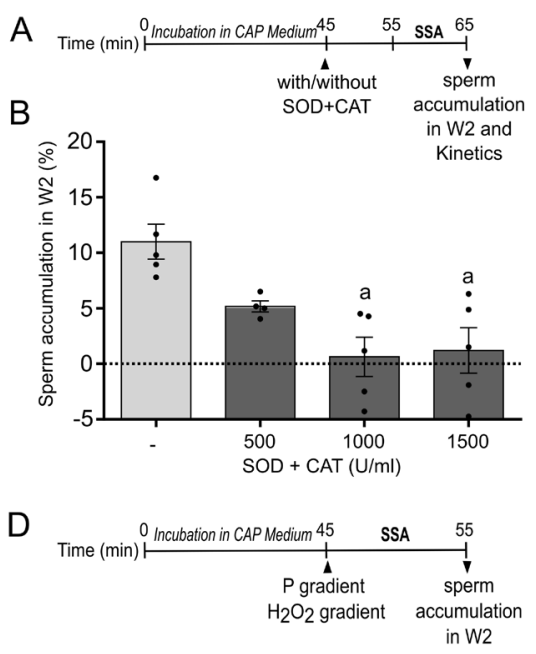

E

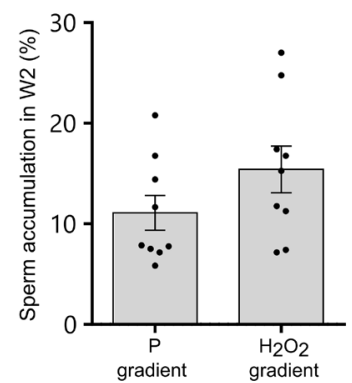

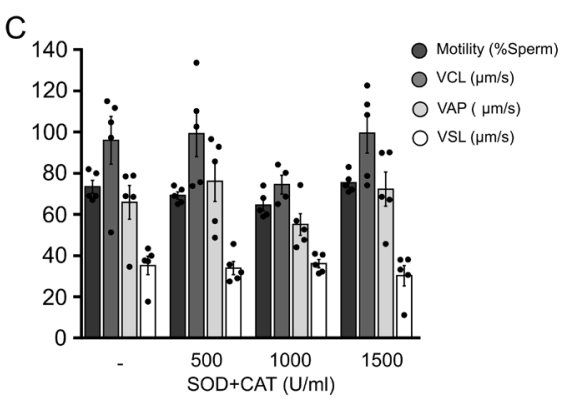

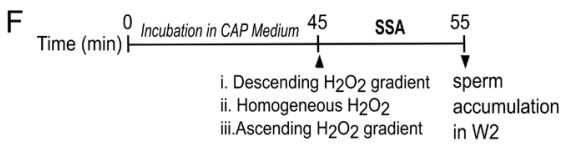

G

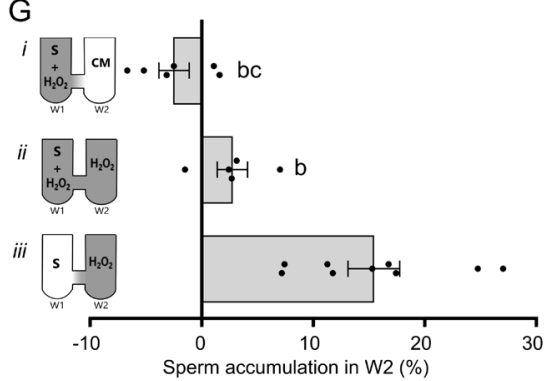

Figure $4 \mathrm{H}_{2} \mathrm{O}_{2}$ participates in the chemotaxis signalling pathway mediated by progesterone. (A, D and F) Experimental design, upward arrowhead indicates treatment applied, downward arrowhead indicates measured parameter. (B) Percentage of sperm accumulation in W2 after being preincubated with different concentrations of antioxidants. (C) Sperm kinematic parameters after the antioxidant treatment. (E) Percentage of sperm accumulation in $\mathrm{W} 2$ after being exposed to a gradient generated by $10 \mathrm{pM}$ of $\mathrm{P}$ or $0.2 \mathrm{mM}$ of $\mathrm{H}_{2} \mathrm{O}_{2}$. (G) Percentage of sperm accumulation in $\mathrm{W} 2$ in presence of a descending gradient of $\mathrm{H}_{2} \mathrm{O}_{2}$ (i), an homogeneous concentration of $\mathrm{H}_{2} \mathrm{O}_{2}$ (ii), and an ascending gradient of $\mathrm{H}_{2} \mathrm{O}_{2}$ (iii); The SSA showing the experimental design for each treatment are shown in the left. $\mathrm{P}$,

progesterone; $\mathrm{CM}$, culture medium; $\mathrm{S}$, sperm; SOD, superoxide dismutase; CAT, catalase; VCL, curvilinear velocity; $\mathrm{VAP}$, mean trajectory velocity; VSL, straight-line velocity. The black dots represent individual experiments. The results are presented as the mean \pm S.E.M. of at least five experiments performed with ejaculates from three different horses. aSignificant differences vs control without antioxidants, bSignificant differences vs ascending gradient of $\mathrm{H}_{2} \mathrm{O}_{2}$, 'Significant differences vs homogeneous concentration of $\mathrm{H}_{2} \mathrm{O}_{2}(P<0.05)$. the AC. We next investigate whether the chemotactic signal stimulated by the $\mathrm{H}_{2} \mathrm{O}_{2}$ gradient was suppressed by inhibiting PKA. Capacitated spermatozoa were incubated with different concentrations of H89, a specific inhibitor of PKA (Lochner \& Moolman 2006). Treatment with H89 significantly decreased the chemotactic response of spermatozoa exposed to a gradient generated by $0.2 \mathrm{mM}$ of $\mathrm{H}_{2} \mathrm{O}_{2}$, in a dosedependent manner $(P<0.0001)$; a similar result was observed in the corresponding P positive control (Fig. 5C). These results show that $\mathrm{H}_{2} \mathrm{O}_{2}$ may play a role prior to the activation of PKA. To evaluate whether $\mathrm{H}_{2} \mathrm{O}_{2}$ participates upstream protein tyrosine phosphorylation, capacitated spermatozoa were incubated with different doses of PF431396, a specific inhibitor for the tyrosine protein kinase 2 (PYK2) and tyrosine protein kinase FER (Alvau et al. 2016). Results presented in Fig. 5D show that the inhibitor significantly decreased the chemotactic response of sperm exposed to a gradient generated by $0.2 \mathrm{mM}$ of $\mathrm{H}_{2} \mathrm{O}_{2}$, in a dose-dependent manner; similar results were observed in the corresponding $\mathrm{P}$ control $(P<0.0001)$. These results suggest that the increase in $\mathrm{H}_{2} \mathrm{O}_{2}$ occurs before the phosphorylation of proteins on tyrosine residues mediated by FER and PYK2 enzymes. Taking into account that the intracellular calcium increase is one of the events that occur during the chemotactic signal (Teves et al. 2009), we evaluated whether this phenomenon occurs before or after the increase in intracellular $\mathrm{H}_{2} \mathrm{O}_{2}$. Capacitated sperm were incubated with different concentrations of the intracellular calcium chelator, BAPTA-AM, and then exposed to a gradient of $\mathrm{H}_{2} \mathrm{O}_{2}$, or $\mathrm{P}$ as a control. Treatment with BAPTA-AM significantly decreased the chemotactic response of spermatozoa exposed to a gradient generated by $0.2 \mathrm{mM}$ of $\mathrm{H}_{2} \mathrm{O}_{2}$ in a dose-dependent manner, like the $\mathrm{P}$ control $(P<0.0001)$ (Fig. 5E). These results suggest that $\mathrm{H}_{2} \mathrm{O}_{2}$ play a role probably before the intracellular calcium increase.

Considering that there must be an enzyme that produces ROS immediately after binding $\mathrm{P}$ to its receptor, we next investigated whether NOX5 (an enzyme located in the sperm plasma membrane in equine spermatozoa (Sabeur \& Ball 2007) that produce ROS in some mammalian spermatozoa (Sabeur \& Ball 2007, Musset et al. 2012, Setyawan et al. 2016)), is involved in sperm chemotaxis mediated by $P$. Capacitated spermatozoa were incubated with different concentrations of DPI (a generic inhibitor of several flavoproteins; Li \& Trush 1998), and then exposed to a gradient generated by $\mathrm{H}_{2} \mathrm{O}_{2}$ or $\mathrm{P}$ as a control (Fig. 6A). Treatment with DPI significantly decreased the chemotactic response of sperm exposed to a $P$ gradient in a dose-dependent manner $(P<0.0001)$, but not to a $\mathrm{H}_{2} \mathrm{O}_{2}$ gradient $(P=0.0656$; Fig. $6 \mathrm{~B})$. To evaluate 
A

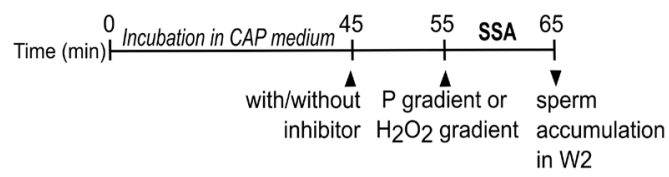

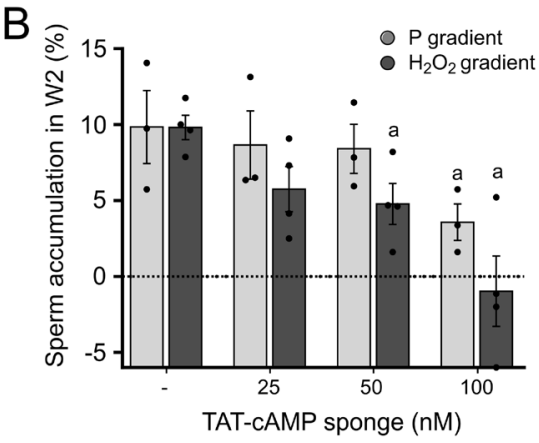

D

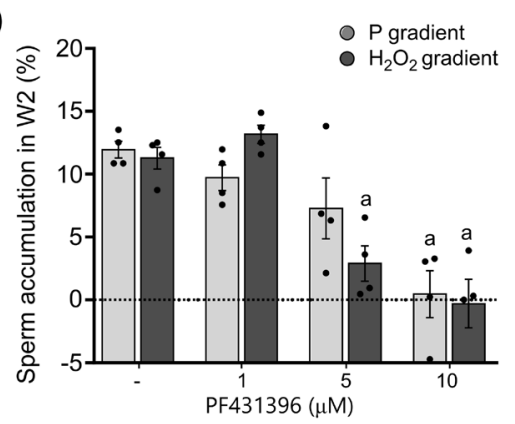

C

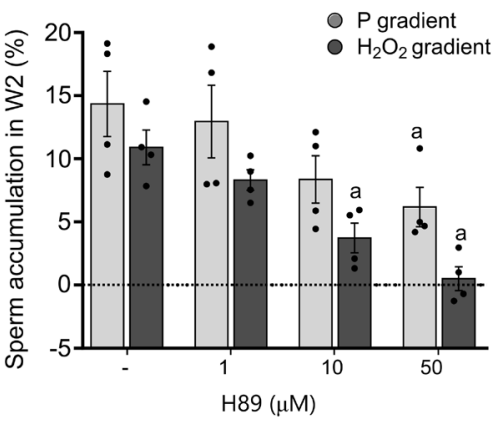

$\mathrm{E}$

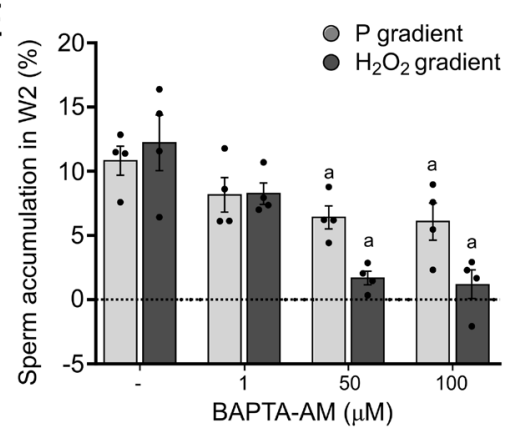

Figure $5 \mathrm{H}_{2} \mathrm{O}_{2}$ is involved in the cAMP-PKA chemotaxis signaling by progesterone $(\mathrm{P})$. (A) Experimental design, where upward arrowhead indicates treatment applied, downward arrowhead indicates measured parameter. Percentage of sperm accumulation in W2 after exposure to a gradient generated by $0.2 \mathrm{mM}$ of $\mathrm{H}_{2} \mathrm{O}_{2}$ or $10 \mathrm{pM}$ of $\mathrm{P}$, previously incubated with different doses of: (B) TAT-cAMP sponge, a chelator of cAMP, (C) H89, an inhibitor of PKA, (D) PF431396, an inhibitor of protein tyrosine phosphorylation, and (E) BAPTAAM, a chelator of the intracellular calcium. The black dots represent individual experiments. SSA, sperm selection assay; $\mathrm{P}$, progesterone. The results are presented as the mean \pm S.E.M. of at least three experiments with ejaculates from three different horses. ${ }^{\text {aSignificant difference vs }}$ without inhibitor $(P<0.05)$. whether the $\mathrm{H}_{2} \mathrm{O}_{2}$ involved in chemotaxis is produced by NOX5 which is activated by calcium (Bánfi et al. 2004), capacitated spermatozoa were treated with or without DPI or BAPTA-AM and exposed to a P gradient, determining total $\mathrm{O}_{2}{ }^{--}$production by DHE (Fig. 6C). ROS levels decreased in a dose dependent manner when spermatozoa were exposed to a $\mathrm{P}$ gradient in the presence of DPI $(P=0.0004$; Fig. $6 \mathrm{D}$ and $\mathrm{E})$ as well as under the presence of BAPTA-AM $(P=0.0001$; Fig. $6 \mathrm{~F}$ and $\mathrm{G})$. These results suggest that NOX5 may be responsible for ROS production during the chemotaxis signaling. It is worth noting that the range of concentration of inhibitors and chelators used in this study (TAT-AMPc sponge: 0-100 nM; H89: 0-50 $\mu \mathrm{M}$; PF431396: 0-10 $\mu \mathrm{M}$; DPI: 0-1 $\mu$ M; BAPTA-AM: 0-100 $\mu \mathrm{M}$ ) did not affect the sperm kinematic parameters, meaning that only chemotaxis was interfered (Fig. 7).

\section{Discussion}

ROS have a dual effect on sperm. On one hand, they participate in the regulation of sperm capacitation, a required event for fertilization (Aitken et al. 1995, 1998, de Lamirande \& Gagnon 1995, Lewis \& Aitken 2001, Baumber et al. 2003, Ecroyd et al. 2003, Villegas et al. 2003, O'Flaherty et al. 2005, 2006a, Boerke et al. 2013). On the other hand, an excessive production of ROS leads to oxidative stress negatively affecting sperm function (Aitken et al. 2012, Aitken 2017). The latter is due to the fact that once oxidative stress has begun, it increases over time, as a direct consequence of lipid peroxidation, which alters membrane-dependent sperm functions (e.g., motility), triggering a greater generation of ROS in mitochondria, leading to apoptosis (Moazamian et al. 2015). Thus, the intracellular amount of ROS may be a pivotal key for their dual effect on sperm physiology. In this work we show that the level of intracellular $\mathrm{O}_{2}{ }^{--}$increases under capacitating conditions in equine sperm, in agreement with other reports in this and other species (Baumber et al. 2003, O'Flaherty et al. 2003, de Lamirande \& Lamothe 2009, Donà et al. 2011).

An oxidase apparently exclusive of the spermatozoon, which is located mainly in the plasma membrane of several mammalian species, including equine, is responsible for the production of part of the ROS which are delivered to the extracellular space, to then return inside the cell; however, the participation of cytosolic oxidases cannot be ruled out (Bize et al. 1991, Griveau et al. 1994, Aitken et al. 1995, Baumber et al. 2003, O'Flaherty 2015). In equine sperm, it was observed that most endogenous ROS are produced by NADH dehydrogenase at complex 1 of the mitochondrial electron transport chain, because oxidative phosphorylation is the main source of energy in these cells (Gibb et al. 2014, Gibb \& Aitken 2016). 

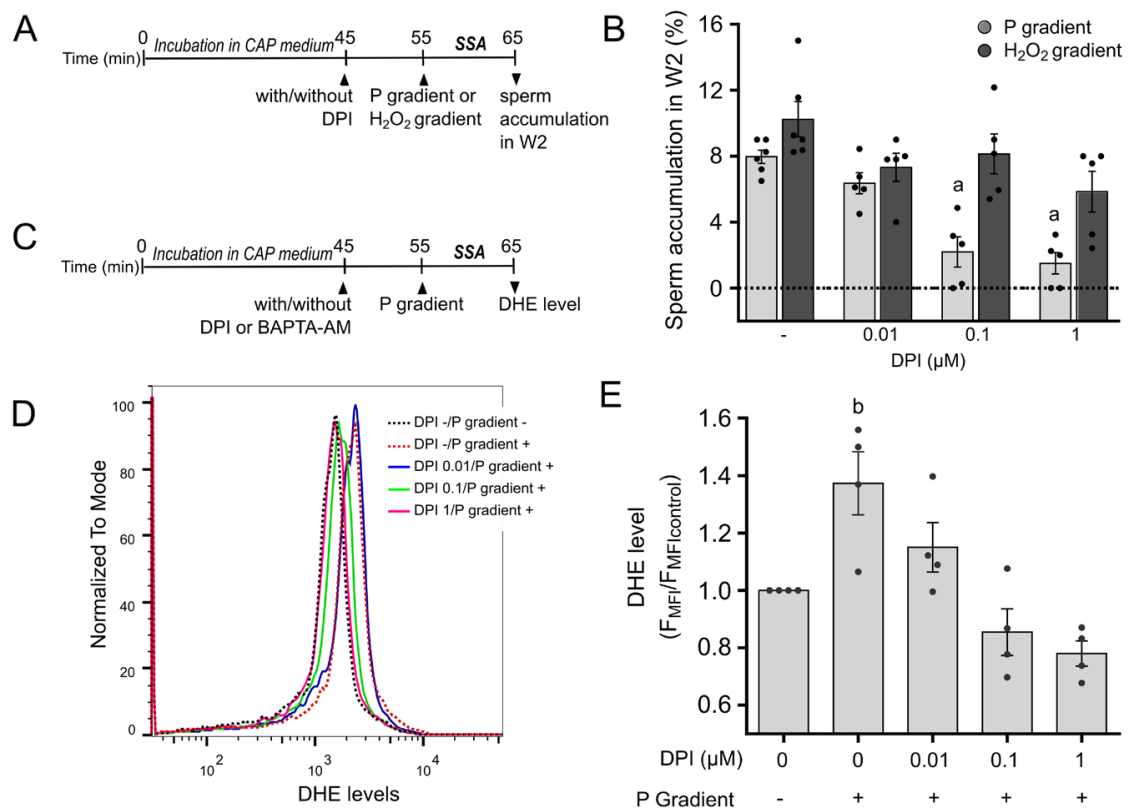

$E$

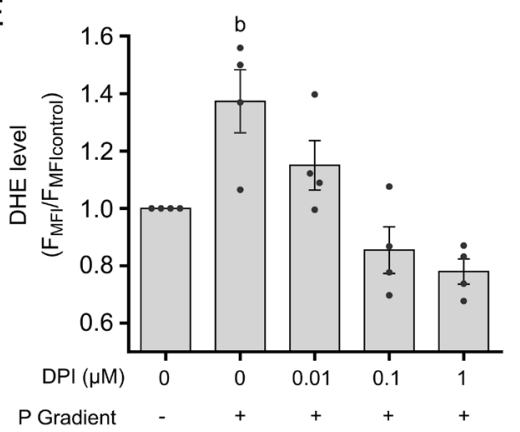

F

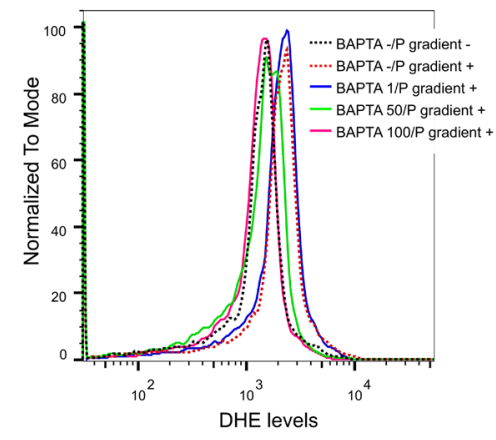

G

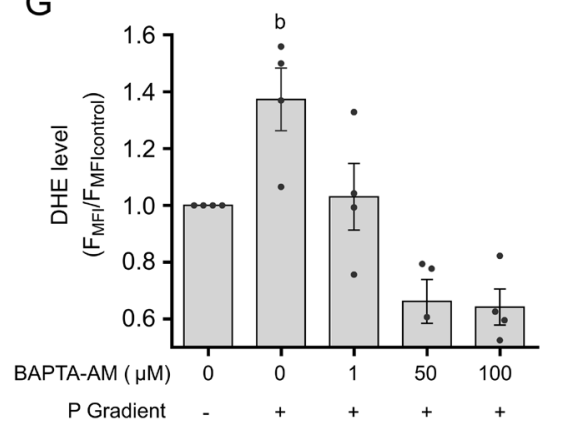

Figure $6 \mathrm{H}_{2} \mathrm{O}_{2}$ involved in the chemotactic signaling towards $\mathrm{P}$ could be produced by NOX5. (A) Experimental design for panel B, upward arrowhead indicates treatment applied, downward arrowhead indicates measured parameter, DPI an inhibitor of NOX5. (B) Percentage of sperm accumulation in $\mathrm{W} 2$ after exposure to a gradient generated by $0.2 \mathrm{mM}$ of $\mathrm{H}_{2} \mathrm{O}_{2}$ or $10 \mathrm{pM}$ of $\mathrm{P}$, previously incubated with different doses of DPI. (C) Experimental design for panels (D, E, F and G), upward arrowhead indicates treatment applied, downward arrowhead indicates measured parameter. ( $D$ and F) Representative example of one experiment. (E and G) Endogenous production of ROS after exposure to a gradient generated by $10 \mathrm{pM}$ of $\mathrm{P}$, previously incubated with different doses of DPI or BAPTA-AM respectively. P, progesterone; SSA, sperm selection assay; $\mathrm{MFI}$, mean fluorescence intensity. The black dots represent individual experiments. The results are presented as the mean \pm S.E.M. of at least three experiments with ejaculates from three different horses. ${ }^{\text {SSignificant difference vs }}$ without inhibitor. ${ }^{\mathrm{b}}$ Significant differences vs without $\mathrm{P}$ gradient $(P<0.05)$.
In this study, the exogenous addition of $\mathrm{H}_{2} \mathrm{O}_{2}$, which is permeable to the plasma membrane, may also stimulate capacitation and other sperm functions. Thus, a range between $0.1 \mathrm{mM}-0.2 \mathrm{mM}$ of $\mathrm{H}_{2} \mathrm{O}_{2}$ stimulate the occurrence of sperm parameters associated with capacitation, such as protein phosphorylation on tyrosine residues, the induction of the $A R$, and the chemotactic selection of equine spermatozoa which was shown for the first time by us, without causing oxidative stress. Moreover, this effect was reversed by the addition of antioxidants. On the contrary, higher doses of $\mathrm{H}_{2} \mathrm{O}_{2}(0.4 \mathrm{mM})$ significantly decrease the parameters associated with sperm capacitation, observing oxidative stress only in lipid peroxidation (Jones \& Mann 1977, Jones et al. 1979, Aitken et al. 1989, de Lamirande et al. 1997). In this study we observed that $0.2 \mathrm{mM}$ $\mathrm{H}_{2} \mathrm{O}_{2}$ stimulates sperm function in contrast to the results obtained by Morielli and O'Flaherty (2015) who observed a decrease in the induced $A R$ when human spermatozoa were incubated with $0.25 \mathrm{mM} \mathrm{H}_{2} \mathrm{O}_{2}$. This apparent controversy may be due to several facts. Our study was performed in equine spermatozoa which energetic metabolism is different from that of human sperm; we used a lower concentration of $\mathrm{H}_{2} \mathrm{O}_{2}(0.2 \mathrm{mM}$ vs $0.25 \mathrm{mM}$ ) which stimulate sperm function without inducing oxidative stress, nor affecting cell viability and kinematic; even though in our study the percentage of motile cells decreased around $20 \%$ with $0.2 \mathrm{mM} \mathrm{H}_{2} \mathrm{O}_{2}$ (vs. $50 \%$ in their study) those moving spermatozoa show good kinematic parameters. Our findings are in agreement with previous studies which reported that similar concentrations of $\mathrm{H}_{2} \mathrm{O}_{2}$, stimulate PY in bovine, while higher concentrations of $\mathrm{H}_{2} \mathrm{O}_{2}$ are detrimental for spermatozoa (Rivlin et al. 2004). Interestingly, the induction of $\mathrm{H}_{2} \mathrm{O}_{2}$ production stimulates $\mathrm{PY}$ and the induced $A R$ in equine spermatozoa (Baumber et al. 2003). Likewise, high levels of ROS produced by pharmacological induction, during a capacitating incubation for $4 \mathrm{~h}$, inhibit the chemotactic response of human sperm to follicular fluid (Sánchez et al. 2010).

The involvement of ROS in chemotaxis is well known in other cell types such as neutrophils (Niethammer et al. 2009, Kuiper et al. 2011, Nathan \& CunninghamBussel 2013). Since sperm chemotaxis is dependent on capacitation and ROS participate in the capacitation signaling via AMPc-PKA (O'Flaherty et al. 2004, 2006a, O'Flaherty 2015), which is the same pathway activated in the chemotaxis response (Teves et al. 2009) and 

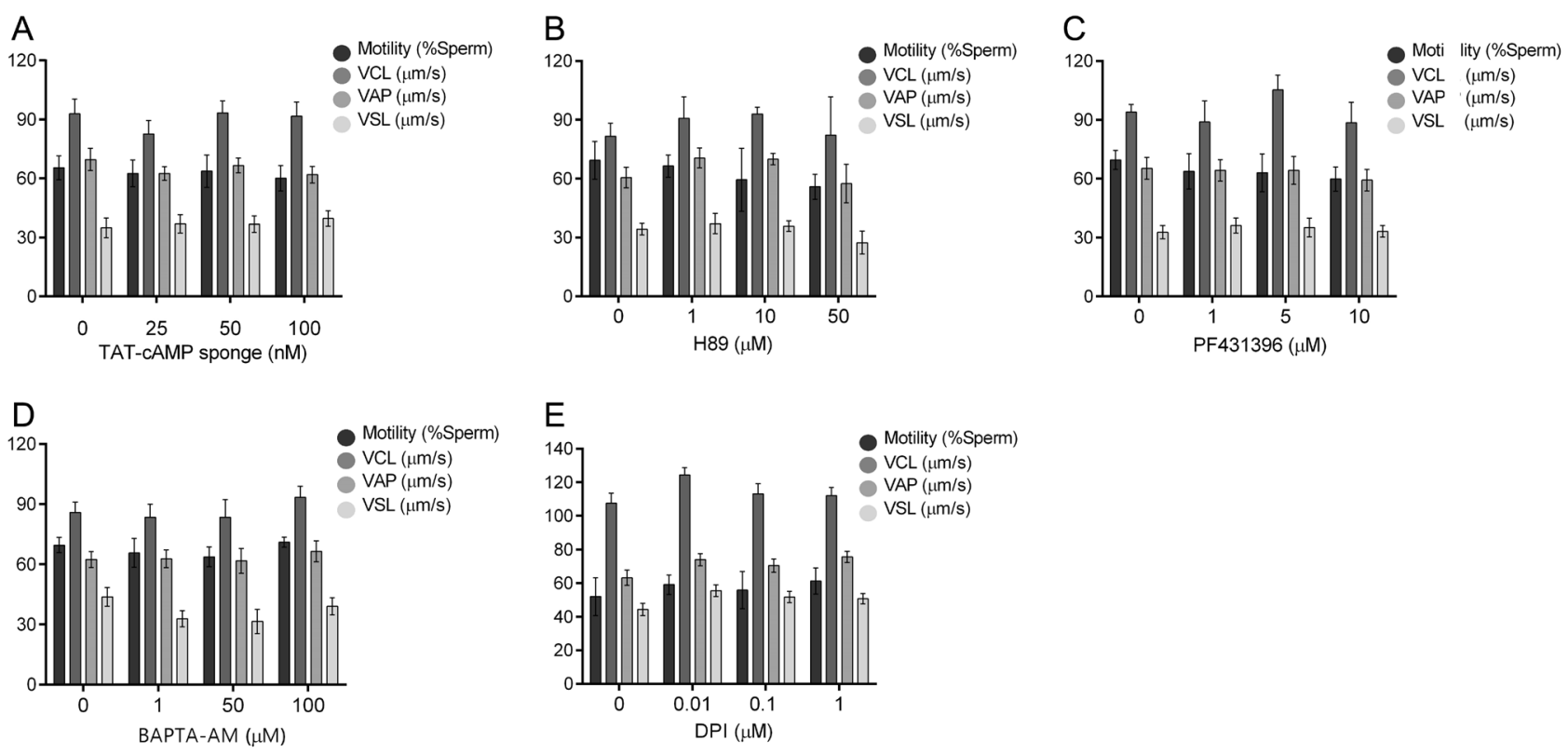

Figure 7 Sperm kinematic parameters are not affected by inhibitors/chelators of components of the chemotaxis signaling. (A) TAT-cAMP sponge, a chelator of cAMP; (B) H89, an inhibitor of PKA; (C) PF431396, an inhibitor of protein tyrosine phosphorylation, (D) BAPTA-AM, a chelator of the intracellular calcium; (E) DPI, an inhibitor of NOX. VCL, curvilinear velocity; VAP, mean trajectory velocity; VSL, straight line velocity. Results are presented as the mean \pm S.E.M. of at least four experiments with ejaculates from three different horses.

that the sperm chemotaxis can be stimulated by nitric oxide (one of the nitrogen oxidative species) (Miraglia et al. 2007), it is probable that ROS also modulate the molecular mechanism of chemotaxis.

We investigated the participation of $\mathrm{H}_{2} \mathrm{O}_{2}$ in chemotaxis by two different strategies: (1) inhibition of chemotaxis by antioxidants; (2) activation of the chemotactic signal by the gradual intracellular increase of $\mathrm{H}_{2} \mathrm{O}_{2}$, in sperm exposed to a gradient of $\mathrm{H}_{2} \mathrm{O}_{2}$ in the absence of $\mathrm{P}$. Here we observed for the first time that, not only ROS are part of the AMPC-PKA signaling pathway that modulates sperm chemotaxis in stallion, but also that, similar to capacitation (O'Flaherty et al. 2004), the intracellular increase of ROS would be an event prior to the activation of this pathway.

The use of a concentration gradient of $\mathrm{H}_{2} \mathrm{O}_{2}$ combined with the addition of a cAMP chelator, led to the conclusion that $\mathrm{H}_{2} \mathrm{O}_{2}$ production occurs before the activation of the adenylate cyclase. Therefore, there should be some enzyme that produces ROS immediately after $\mathrm{P}$ binding to its receptor. In spermatozoa, NOX5 is an enzyme located in the plasma membrane of equine (Sabeur \& Ball 2007) and human spermatozoa (Musset et al. 2012) that generates ROS by reducing NAD (NADPH). Moreover, this enzyme was shown to participate in the chemotaxis signaling of neutrophils (Woo et al. 2003) and several ROS-mediated signaling in spermatozoa (Aitken et al. 1992, Aitken et al. 1995, 1997, Ball et al. 2001, Armstrong et al. 2002, Sabeur \& Ball 2006). In addition, NOX5 also has the ability to bind to calcium, which leads to the activation of oxidized
$\mathrm{NADPH}$, and thus to the production of ROS (Tirone et al. 2010). Given that a chemotactic gradient of $P$ stimulates an initial increase in intracellular calcium (Teves et al. 2009), and that NOX5 is activated immediately upon an increase in intracellular $\mathrm{Ca}^{2+}$ (Bánfi et al. 2004), this enzyme could mediate the production of intracellular ROS in chemotactic spermatozoa.

The results of this work led to propose a model of part of the molecular mechanism of sperm chemotaxis mediated by P. Thus, after P binding to its receptor, probably located in the plasma membrane, there is a first $\mathrm{Ca}^{2+}$ entry that activates NOX5, an integral membrane protein, generating an increase of ROS. This event, in conjunction with others, stimulates the increase of CAMP, followed by the activation of PKA and the subsequent PY, which after a series of intermediate steps involving $\mathrm{Ca}^{2+}$, lead to the orientation of the flagellar movement toward the P source (Teves et al. 2009).

\section{Declaration of interest}

L C G is one of the inventors of the SSA device, and the Consejo de Investigaciones Científicas y Ténicas and the Universidad Nacional de Córdoba are the owners of the patent. The other authors have nothing to disclose.

\section{Funding}

This study was supported by Secyt-UNC-PID 'A'-2016-2017. 


\section{Author contribution statement}

A M-I designed the study and experiments, performed experiments, analyzed data and wrote the article; E M D assisted A M-I in most of the experiments performed; C I M-B performed the WB for sperm PY; L L obtained and cryopreserved the equine semen samples; $\mathrm{O} L$ generated the TAT-cAMP sponge; $R \mathrm{~L}$ gave us the inhibitor for flavoproteins, participated in the interpretation of data from these experiments, and provided fruitful comments to the manuscript. A M-V and C L T provided the inhibitors PF431396 for two tyrosine protein kinase and $\mathrm{H} 89$ dihydrochloride for PKA and gave advise about the design of these experiments and their interpretation. C N T, C L T, M G B helped us with results presentation and interpretation, providing fruitful comments to the manuscript; L C G designed the study and experiments, got financial support, wrote the article.

\section{Acknowledgments}

$L C G, C N T, C I M-B, M G B$ and $R L$ are researchers of the Consejo Nacional de Investigaciones Científicas y Técnicas (Argentina). A M-I and E M D are fellowship holders of CONICET. The authors thank Dr Pablo Visconti for critically reading the manuscript.

\section{References}

Agarwal A, Gupta S \& Sikka S 2006 The role of free radicals and antioxidants in reproduction. Current Opinion in Obstetrics and Gynecology 18 325-332. (https://doi.org/10.1097/01.gco.0000193003.58158.4e)

Aitken RJ 2017 Reactive oxygen species as mediators of sperm capacitation and pathological damage. Molecular Reproduction and Development 84 1039-1052. (https://doi.org/10.1002/mrd.22871)

Aitken RJ 2018 Not every sperm is sacred; a perspective on male infertility. Molecular Human Reproduction 24 287-298. (https://doi.org/10.1093/ molehr/gay010)

Aitken RJ, Clarkson JS \& Fishel S 1989 Generation of reactive oxygen species, lipid peroxidation, and human sperm function. Biology of Reproduction 41 183-197. (https://doi.org/10.1095/biolreprod41.1.183)

Aitken RJ, Buckingham DW \& West KM 1992 Reactive oxygen species and human spermatozoa: analysis of the cellular mechanisms involved in luminol- and lucigenin-dependent chemiluminescence. Journal of Cellular Physiology 151 466-477. (https://doi.org/10.1002/ jcp.1041510305)

Aitken RJ, Paterson M, Fisher H, Buckingham DW \& van Duin M 1995 Redox regulation of tyrosine phosphorylation in human spermatozoa and its role in the control of human sperm function. Journal of Cell Science 108 2017-2025.

Aitken RJ, Fisher HM, Fulton N, Gomez E, Knox W, Lewis B \& Irvine S 1997 Reactive oxygen species generation by human spermatozoa is induced by exogenous NADPH and inhibited by the flavoprotein inhibitors diphenylene iodonium and quinacrine. Molecular Reproduction and Development 47 468-482. (https://doi.org/10.1002/(SICI)10982795(199708)47:4<468::AID-MRD14>3.0.CO;2-S)

Aitken RJ, Harkiss D, Knox W, Paterson M \& Irvine DS 1998 A novel signal transduction cascade in capacitating human spermatozoa characterised by a redox-regulated, cAMP-mediated induction of tyrosine phosphorylation. Journal of Cell Science 111 645-656.

Aitken RJ, Wingate JK, De Iuliis GN \& McLaughlin EA 2007 Analysis of lipid peroxidation in human spermatozoa using BODIPY C11. Molecular Human Reproduction 13 203-211. (https://doi.org/10.1093/ molehr/gal119] )

Aitken RJ, Whiting S, de luliis GN, McClymont S, Mitchell LA \& Baker MA 2012 Electrophilic aldehydes generated by sperm metabolism activate mitochondrial reactive oxygen species generation and apoptosis by targeting succinate dehydrogenase. Journal of Biological Chemistry 287 33048-33060. (https://doi.org/10.1074/jbc.M112.366690)

Alvau A, Battistone MA, Gervasi MG, Navarrete FA, Xu X, SánchezCárdenas C, De la Vega-Beltran JL, Da Ros VG, Greer PA, Darszon A et al. 2016 The tyrosine kinase fer is responsible for the capacitationassociated increase in tyrosine phosphorylation in murine sperm. Development 143 2325-2333. (https://doi.org/10.1242/dev.136499)

Armstrong JS, Bivalacqua TJ, Chamulitrat W, Sikka S \& Hellstrom WJG 2002 A comparison of the NADPH oxidase in human sperm and white blood cells. International Journal of Andrology 25 223-229. (https://doi. org/10.1046/j.1365-2605.2002.00351.x)

Austin C 1951 Observations on the penetration of the sperm into the mammalian egg. Australian Journal of Scientific Research Ser. B. Biological Sciences 4 581-596. (https://doi.org/10.1071/BI9510581)

Ball BA, Vo AT \& Baumber J 2001 Generation of reactive oxygen species by equine spermatozoa. American Journal of Veterinary Research $\mathbf{6 2}$ 508-515. (https://doi.org/10.2460/ajvr.2001.62.508)

Bánfi B, Tirone F, Durussel I, Knisz J, Moskwa P, Molnár GZ, Krause KH \& Cox JA 2004 Mechanism of Ca2+ activation of the NADPH oxidase 5 (NOX5). Journal of Biological Chemistry 279 18583-18591. (https://doi. org/10.1074/jbc.M310268200)

Barbonetti A, Castellini C, Di Giammarco N, Santilli G, Francavilla S \& Francavilla F 2016 In vitro exposure of human spermatozoa to bisphenol A induces pro-oxidative / apoptotic mitochondrial dysfunction. Reproductive Toxicology 66 61-67. (https://doi.org/10.1016/j. reprotox.2016.09.014)

Baumber J, Sabeur K, Vo A \& Ball BA 2003 Reactive oxygen species promote tyrosine phosphorylation and capacitation in equine spermatozoa. Theriogenology 60 1239-1247. (https://doi.org/10.1016/ S0093-691X(03)00144-4)

Biggers JD, Whitten WK \& Whittingham DG 1971 The culture of mouse embryos in vitro. In Methods in Mammalian Embryology. J C Daniel Jr. (Ed) San Francisco: W. H. Freeman \& Company.

Bize I, Santander G, Cabello P, Driscoll D \& Sharpe C 1991 Hydrogen peroxide is involved in hamster sperm capacitation in vitro. Biology of Reproduction 44 398-403. (https://doi.org/10.1095/biolreprod44.3.398)

Blengini CS, Teves ME, Uñates DR, Guidobaldi HA, Gatica LV \& Giojalas LC 2011 Human sperm pattern of movement during chemotactic reorientation towards a progesterone source. Asian Journal of Andrology 13 769-773. (https://doi.org/10.1038/aja.2011.27)

Boerke A, Brouwers JF, Olkkonen VM, van de Lest CHA, Sostaric E, Schoevers EJ, Helms JB \& Gadella BM 2013 Involvement of bicarbonateinduced radical signaling in oxysterol formation and sterol depletion of capacitating mammalian sperm during in vitro fertilization. Biology of Reproduction 88 21. (https://doi.org/10.1095/biolreprod.112.101253)

Buffone MG 2016 Sperm Acrosome Biogenesis and Function During Fertilization. InAdvances in Anatomy, Embryology and Cell Biology. Switzerland: Springer International Publishing. (https://doi. org/10.1007/978-3-319-30567-7)

Bustos MA, Roggero CM, De la Iglesia PX, Mayorga LS \& Tomes CN 2014 GTP-bound Rab3A exhibits consecutive positive and negative roles during human sperm dense-core granule exocytosis. Journal of Molecular Cell Biology 6 286-298. (https://doi.org/10.1093/jmcb/mju021)

Chang MC 1951 Fertilizing capacity of spermatozoa deposited into the fallopian tubes. Nature 168 697-698. (https://doi. org/10.1038/168697b0)

de Lamirande E \& Gagnon C 1995 Impact of reactive oxygen species on spermatozoa: a balancing act between beneficial and detrimental effects. Human Reproduction 10 (Supplement 1) 15-21. (https://doi. org/10.1093/humrep/10.suppl_1.15)

de Lamirande E \& Lamothe G 2009 Reactive oxygen-induced reactive oxygen formation during human sperm capacitation. Free Radical Biology and Medicine 46 502-510. (https://doi.org/10.1016/j. freeradbiomed.2008.11.004)

de Lamirande E, Jiang H, Zini A, Kodama H \& Gagnon C 1997 Reactive oxygen species and sperm physiology. Reviews of Reproduction 2 48-54. (https://doi.org/10.1530/ror.0.0020048)

Dominguez EM 2019 Application of the Sperm Selection Assay (SSA) to Optimize In Vitro Production of Equine and Bovine Sexed Embryos. Universidad Nacional de Rio Cuarto, Rio Cuarto, Cordoba, Argentina.

Dominguez EM, Moreno-Irusta A, Guidobaldi HA, Tribulo H \& Giojalas LC 2018 Improved bovine in vitro embryo production with 
sexed and unsexed sperm selected by chemotaxis. Theriogenology 122 1-8. (https://doi.org/10.1016/j.theriogenology.2018.08.023)

Donà G, Fiore C, Tibaldi E, Frezzato F, Andrisani A, Ambrosini G, Fiorentin D, Armanini D, Bordin L \& Clari G 2011 Endogenous reactive oxygen species content and modulation of tyrosine phosphorylation during sperm capacitation. International Journal of Andrology 34 411-419. (https://doi.org/10.1111/j.1365-2605.2010.01097.x)

Ecroyd HW, Jones RC \& Aitken RJ 2003 Endogenous redox activity in mouse spermatozoa and its role in regulating the tyrosine phosphorylation events associated with sperm capacitation. Biology of Reproduction 69 347-354. (https://doi.org/10.1095/biolreprod.102.012716)

Eisenbach M \& Giojalas LC 2006 Sperm guidance in mammals - an unpaved road to the egg. Nature Reviews: Molecular Cell Biology 7 276-285. (https://doi.org/10.1038/nrm1893)

Ernesto JI, Weigel Muñoz M, Battistone MA, Vasen G, Martínez-López P, Orta G, Figueiras-Fierro D, De la Vega-Beltran JL, Moreno IA, Guidobaldi HA et al. 2015 CRISP1 as a novel CatSper regulator that modulates sperm motility and orientation during fertilization. Journal of Cell Biology 210 1213-1224. (https://doi.org/10.1083/jcb.201412041)

Florman HM \& Fissore RA 2014 Fertilization in mammals. In Knobil and Neill's Physiology of Reproduction: Two-Volume Set, 4th edition. T M Plant and A J Zeleznik (Eds) New York, USA: Elsevier Inc. (https://doi. org/10.1016/B978-0-12-397175-3.00004-1)

Franchi A, Cubilla M, Guidobaldi HA, Bravo AA \& Giojalas LC 2016 Uterosome-like vesicles prompt human sperm fertilizing capability. Molecular Human Reproduction 22 833-841. (https://doi.org/10.1093/ molehr/gaw066)

Gagnon C, Iwasaki A, De Lamirande E \& Kovalski N 1991 Reactive oxygen species and human spermatozoa. Annals of the New York Academy of Sciences 637 436-444. (https://doi.org/10.1111/j.1749-6632.1991. tb27328.x)

Gatica LV, Guidobaldi HA, Montesinos MM, Teves ME, Moreno AI, Uñates DR, Molina RI \& Giojalas LC 2013 Picomolar gradients of progesterone select functional human sperm even in subfertile samples. Molecular Human Reproduction 19 559-569. (https://doi.org/10.1093/ molehr/gat037)

Giaretta E, Munerato M, Yeste M, Galeati G, Spinaci M, Tamanini C, Mari G \& Bucci D 2017 Implementing an open-access CASA software for the assessment of stallion sperm motility: relationship with other sperm quality parameters. Animal Reproduction Science 176 11-19. (https://doi.org/10.1016/J.ANIREPROSCI.2016.11.003)

Gibb Z \& Aitken RJ 2016 The impact of sperm metabolism during in vitro storage: the stallion as a model. BioMed Research International 2016 9380609. (https://doi.org/10.1155/2016/9380609)

Gibb Z, Lambourne SR \& Aitken RJ 2014 The paradoxical relationship between stallion fertility and oxidative stress. Biology of Reproduction 91 77. (https://doi.org/10.1095/biolreprod.114.118539)

Giojalas LC, Guidobaldi HA \& Sánchez R 2015 Sperm chemotaxis in mammals. In Flagellar Mechanics and Sperm Guidance, J J Cosson (ED) pp. 272-307. Sharjah, UAE: Bentham Science Publishers Ltd. (https:// doi.org/10.2174/9781681081281115010012)

González-Fernández L, Macías-García B, Loux SC, Varner DD \& Hinrichs K 2013 Focal adhesion kinases and calcium/calmodulindependent protein kinases regulate protein tyrosine phosphorylation in stallion sperm. Biology of Reproduction 88138.

Gravance CG, Garner DL, Baumber J \& Ball BA 2000 Assessment of equine sperm mitochondrial function using JC-1. Theriogenology $\mathbf{5 3}$ 1691-1703. (https://doi.org/10.1016/s0093-691x(00)00308-3)

Griveau JF \& Le Lannou D 1997 Reactive oxygen species and human spermatozoa: physiology and pathology. International Journal of Andrology 20 61-69. (https://doi.org/10.1046/j.13652605.1997.00044.x)

Griveau JF, Renard P \& Le Lannou D 1994 An in vitro promoting role for hydrogen peroxide in human sperm capacitation. International Journal of Andrology 17 300-307. (https://doi.org/10.1111/j.1365-2605.1994. tb01260.x)

Guidobaldi HA, Teves ME, Uñates DR, Anastasía A \& Giojalas LC 2008 Progesterone from the cumulus cells is the sperm chemoattractant secreted by the rabbit oocyte cumulus complex. PLOS ONE 3 e3040. (https://doi.org/10.1371/journal.pone.0003040)

Guidobaldi HA, Cubilla M, Moreno A, Molino MV, Bahamondes L \& Giojalas LC 2017 Sperm chemorepulsion, a supplementary mechanism to regulate fertilization. Human Reproduction 32 1560-1573. (https:// doi.org/10.1093/humrep/dex232)

Gundersen RW \& Barrett JN 1980 Characterization of the turning response of dorsal root neurites toward nerve growth factor. Journal of Cell Biology 87 546-554. (https://doi.org/10.1083/jcb.87.3.546)

Halliwell B 2006 Oxidative stress and neurodegeneration: where are we now? Journal of Neurochemistry 97 1634-1658. (https://doi. org/10.1111/j.1471-4159.2006.03907.x)

Halliwell B \& Gutteridge JMC 2015 Cellular responses to oxidative stress: adaptation, damage, repair, senescence and death. In Free Radicals in Biology and Medicine. Fifth Edition. Eds. B Halliwell \& JMC Gutteridge. New York: Oxford University Press.

Herrero M, Chatterjee S, Lefièvre L, de Lamirande E \& Gagnon C 2000 Nitric oxide interacts with the CAMP pathway to modulate capacitation of human spermatozoa. Free Radical Biology and Medicine 29 522-536. (https://doi.org/10.1016/s0891-5849(00)00339-7)

Herrero MB, de Lamirande E \& Gagnon C 2003 Nitric oxide is a signaling molecule in spermatozoa. Current Pharmaceutical Design 9 419-425. (https://doi.org/10.2174/1381612033391720)

Jaiswal BS, Cohen-Dayag A, Tur-Kaspa I \& Eisenbach M 1998 Sperm capacitation is, after all, a prerequisite for both partial and complete acrosome reaction. FEBS Letters 427 309-313. (https://doi.org/10.1016/ S0014-5793(98)00455-4)

Jones R \& Mann T 1977 Toxicity of exogenous fatty acid peroxides towards spermatozoa. Journal of Reproduction and Fertility $\mathbf{5 0} 255-260$. (https:// doi.org/10.1530/jrf.0.0500255)

Jones R, Mann T \& Sherins R 1979 Peroxidative breakdown of phospholipids in human spermatozoa, spermicidal properties of fatty acid peroxides, and protective action of seminal plasma. Fertility and Sterility 31 531-537. (https://doi.org/10.1016/S0015-0282(16)43999-3)

Kuiper JWP, Sun C, Magalhães MAO \& Glogauer M 2011 Rac regulates PtdlnsP3signaling and the chemotactic compass through a redoxmediated feedback loop. Blood 118 6164-6171. (https://doi. org/10.1182/blood-2010-09-310383)

Lefièvre L, Jha KN, de Lamirande E, Visconti PE \& Gagnon C 2002 Activation of protein kinase A during human sperm capacitation and acrosome reaction. Journal of Andrology 23 709-716.

Lewis B \& Aitken RJ 2001 A redox-regulated tyrosine phosphorylation cascade in rat spermatozoa. Journal of Andrology 22 611-622.

Li Y \& Trush MA 1998 Diphenyleneiodonium, an NAD(P)H oxidase inhibitor, also potently inhibits mitochondrial reactive oxygen species production. Biochemical and Biophysical Research Communications 253 295-299. (https://doi.org/10.1006/bbrc.1998.9729)

Lochner A \& Moolman JA 2006 The many faces of H89: a review. Cardiovascular Drug Reviews 24 261-274. (https://doi.org/10.1111/ j.1527-3466.2006.00261.x)

Lucchesi O, Ruete MC, Bustos MA, Quevedo MF\& Tomes CN 2016 The signaling module CAMP/Epac/Rap1/PLCE/IP3 mobilizes acrosomal calcium during sperm exocytosis. Biochimica et Biophysica Acta 1863 544-561. (https://doi.org/10.1016/J.BBAMCR.2015.12.007)

Marín-Briggiler $\mathrm{Cl}$, Vazquez-Levin $\mathrm{MH}$, Gonzalez-Echeverría $\mathrm{F}$, Blaquier JA, Tezón JG \& Miranda PV 1999 Strontium supports human sperm capacitation but not follicular fluid-induced acrosome reaction. Biology of Reproduction 61 673-680. (https://doi.org/10.1095/ biolreprod61.3.673)

Matamoros-Volante A, Moreno-Irusta A, Torres-Rodriguez P, Giojalas L, Gervasi MG, Visconti PE \& Treviño CL 2018 Semi-automatized segmentation method using image-based flow cytometry to study sperm physiology: the case of capacitation-induced tyrosine phosphorylation. Molecular Human Reproduction 24 64-73. (https://doi.org/10.1093/molehr/gax062)

Miraglia E, Rullo ML, Bosia A, Massobrio M, Revelli A \& Ghigo D 2007 Stimulation of the nitric oxide/cyclic guanosine monophosphate signaling pathway elicits human sperm chemotaxis in vitro. Fertility and Sterility 87 1059-1063. (https://doi.org/10.1016/j.fertnstert.2006.07.1540)

Moazamian R, Polhemus A, Connaughton H, Fraser B, Whiting S, Gharagozloo P \& Aitken RJ 2015 Oxidative stress and human spermatozoa: diagnostic and functional significance of aldehydes generated as a result of lipid peroxidation. Molecular Human Reproduction 21 502-515. (https://doi.org/10.1093/molehr/gav014)

Morielli T \& O'Flaherty C 2015 Oxidative stress impairs function and increases redox protein modifications in human spermatozoa. Reproduction 149 113-123. (https://doi.org/10.1530/REP-14-0240) 
Musset B, Clark RA, DeCoursey TE, Petheo GL, Geiszt M, Chen Y, Cornell JE, Eddy CA, Brzyski RG \& Jamali A 2012 NOX5 in human spermatozoa: expression, function, and regulation. Journal of Biological Chemistry 287 9376-9388. (https://doi.org/10.1074/jbc.M111.314955)

Nakanishi T, Ikawa M, Yamada S, Toshimori K \& Okabe M 2001 Alkalinization of acrosome measured by GFP as a $\mathrm{pH}$ indicator and its relation to sperm capacitation. Developmental Biology 237 222-231. (https://doi.org/10.1006/dbio.2001.0353)

Nathan C \& Cunningham-Bussel A 2013 Beyond oxidative stress: an immunologist's guide to reactive oxygen species. Nature Reviews: Immunology 13 349-361. (https://doi.org/10.1038/nri3423)

Niethammer P, Grabher C, Look AT \& Mitchison TJ 2009 A tissue-scale gradient of hydrogen peroxide mediates rapid wound detection in zebrafish. Nature 459 996-999. (https://doi.org/10.1038/nature08119)

O'Flaherty C 2015 Redox regulation of mammalian sperm capacitation. Asian Journal of Andrology 17 583-590. (https://doi.org/10.4103/1008682X.153303)

O'Flaherty C, Beorlegui N \& Beconi MT 2003 Participation of superoxide anion in the capacitation of cryopreserved bovine sperm. International Journal of Andrology 26 109-114. (https://doi.org/10.1046/j.13652605.2003.00404.x)

O'Flaherty C, de Lamirande E \& Gagnon C 2004 Phosphorylation of the arginine-X-X-(serine/threonine) motif in human sperm proteins during capacitation: modulation and protein kinase A dependency. Molecular Human Reproduction 10 355-363. (https://doi.org/10.1093/molehr/ gah046)

O'Flaherty C, Breininger E, Beorlegui N \& Beconi MT 2005 Acrosome reaction in bovine spermatozoa: role of reactive oxygen species and lactate dehydrogenase C4. Biochimica et biophysica acta 1726 96-101. (https://doi.org/10.1016/j.bbagen.2005.07.012)

O'Flaherty C, de Lamirande E \& Gagnon C 2006a Positive role of reactive oxygen species in mammalian sperm capacitation: triggering and modulation of phosphorylation events. Free Radical Biology and Medicine 41 528-540. (https://doi.org/10.1016/j.freeradbiomed.2006.04.027)

O'Flaherty C, de Lamirande E \& Gagnon C 2006b Reactive oxygen species modulate independent protein phosphorylation pathways during human sperm capacitation. Free Radical Biology and Medicine 40 1045-1055. (https://doi.org/10.1016/j.freeradbiomed.2005.10.055)

Pommer AC, Rutllant J \& Meyers SA 2003 Phosphorylation of protein tyrosine residues in fresh and cryopreserved stallion spermatozoa under capacitating conditions. Biology of Reproduction 68 1208-1214. (https://doi.org/10.1095/biolreprod.102.011106)

Puga Molina LC, Luque GM, Balestrini PA, Marín-Briggiler $\mathrm{Cl}$, Romarowski A \& Buffone MG 2018 Molecular basis of human sperm capacitation. Frontiers in Cell and Developmental Biology 6 72. (https:// doi.org/10.3389/fcell.2018.00072)

Risopatrón J, Sánchez R, Sepúlveda N, Peña P, Villagran E \& Miska W 1996 Migration/sedimentation sperm selection method used in bovine in vitro fertilization: comparison with washing/centrifugation. Theriogenology 46 65-73. (https://doi.org/10.1016/0093-691X(96)00142-2)

Rivlin J, Mendel J, Rubinstein S, Etkovitz N \& Breitbart H 2004 Role of hydrogen peroxide in sperm capacitation and acrosome reaction. Biology of Reproduction 70 518-522. (https://doi.org/10.1095/ biolreprod.103.020487)

Sabeur K \& Ball BA 2006 Detection of superoxide anion generation by equine spermatozoa. American Journal of Veterinary Research 67 701-706. (https://doi.org/10.2460/ajvr.67.4.701)

Sabeur K \& Ball BA 2007 Characterization of NADPH oxidase 5 in equine testis and spermatozoa. Reproduction 134 263-270. (https://doi. org/10.1530/REP-06-0120)

Sánchez R, Sepúlveda C, Risopatrón J, Villegas J \& Giojalas LC 2010 Human sperm chemotaxis depends on critical levels of reactive oxygen species. Fertility and Sterility 93 150-153. (https://doi.org/10.1016/j. fertnstert.2008.09.049)

Setyawan EMN, Kim MJ, Oh HJ, Kim GA, Jo YK, Lee SH, Choi YB \& Lee BC 2016 Spermine reduces reactive oxygen species levels and decreases cryocapacitation in canine sperm cryopreservation. Biochemical and Biophysical Research Communications 479 927-932. (https://doi. org/10.1016/J.BBRC.2016.08.091)

Sikka SC, Rajasekaran M \& Hellstrom WJ 1995 Role of oxidative stress and antioxidants in male infertility. Journal of Andrology 16 464-468.

Teves ME, Barbano F, Guidobaldi HA, Sanchez R, Miska W \& Giojalas LC 2006 Progesterone at the picomolar range is a chemoattractant for mammalian spermatozoa. Fertility and Sterility 86 745-749. (https://doi. org/10.1016/j.fertnstert.2006.02.080)

Teves ME, Guidobaldi HA, Uñates DR, Sanchez R, Miska W, Publicover SJ, Morales Garcia AA \& Giojalas LC 2009 Molecular mechanism for human sperm chemotaxis mediated by progesterone. PLOS ONE 4 e8211. (https://doi.org/10.1371/journal.pone.0008211)

Teves ME, Guidobaldi HA, Uñates DR, Sanchez R, Miska W \& Giojalas LC 2010 Progesterone sperm chemoattraction may be modulated by its corticosteroid-binding globulin carrier protein. Fertility and Sterility 93 2450-2452. (https://doi.org/10.1016/j.fertnstert.2009.09.012)

Tirone F, Radu L, Craescu CT \& Cox JA 2010 Identification of the binding site for the regulatory calcium-binding domain in the catalytic domain of NOX5. Biochemistry 49 761-771. (https://doi.org/10.1021/bi901846y)

Villegas J, Kehr K, Soto L, Henkel R, Miska W \& Sánchez R 2003 Reactive oxygen species induce reversible capacitation in human spermatozoa. Andrologia 35 227-232. (https://doi.org/10.1046/j.14390272.2003.00564.x)

Visconti PE, Bailey JL, Moore GD, Pan D, Olds-Clarke P \& Kopf GS 1995a Capacitation of mouse spermatozoa. I. Correlation between the capacitation state and protein tyrosine phosphorylation. Development 121 1129-1137.

Visconti PE, Moore GD, Bailey JL, Leclerc P, Connors SA, Pan D, OldsClarke P \& Kopf GS 1995 b Capacitation of mouse spermatozoa. II. Protein tyrosine phosphorylation and capacitation are regulated by a cAMP-dependent pathway. Development 121 1139-1150.

Visconti PE, Krapf D, de la Vega-Beltrán JL, Acevedo JJ \& Darszon A 2011 Ion channels, phosphorylation and mammalian sperm capacitation. Asian Journal of Andrology 13 395-405. (https://doi.org/10.1038/ aja.2010.69)

Woo CH, Yoo MH, You HJ, Cho SH, Mun YC, Seong CM \& Kim JH 2003 Transepithelial migration of neutrophils in response to leukotriene B4 is mediated by a reactive oxygen species-extracellular signal-regulated kinase-linked cascade. Journal of Immunology 170 6273-6279. (https:// doi.org/10.4049/jimmunol.170.12.6273)

Zhang H \& Zheng RL 1996 Promotion of human sperm capacitation by superoxide anion. Free Radical Research 24 261-268. (https://doi. org/10.3109/10715769609088023)

Zoppino FCM, Halón ND, Bustos MA, Pavarotti MA \& Mayorga LS 2012 Recording and sorting live human sperm undergoing acrosome reaction. Fertility and Sterility 97 1309-1315. (https://doi.org/10.1016/j. fertnstert.2012.03.002)

Received 7 October 2019

First decision 11 December 2019

Revised manuscript received 23 December 2019

Accepted 21 January 2020 